\title{
Density-dependent growth of Alaska sockeye salmon in relation to climate-oceanic regimes, population abundance, and body size, 1925 to 1998
}

\author{
Ellen C. Martinson ${ }^{1, *}$, John H. Helle ${ }^{1}$, Dennis L. Scarnecchia ${ }^{2}$, Houston H. Stokes ${ }^{3}$ \\ ${ }^{1}$ Alaska Fisheries Science Center, National Marine Fisheries Service, National Oceanic and Atmospheric Administration \\ (NOAA), 17109 Point Lena Loop Road, Juneau, Alaska 99801, USA \\ ${ }^{2}$ Department of Fish and Wildlife Resources, University of Idaho, Moscow, Idaho 83844, USA \\ ${ }^{3}$ Department of Economics, University of Illinois at Chicago, 601 S. Morgan Street, Chicago, Illinois 60607, USA
}

\begin{abstract}
To better understand how densitydependent growth of ocean-dwelling Pacific salmon varied with climate and population dynamics, we examined the marine growth of sockeye salmon Oncorhynchus nerka in relation to an index of sockeye salmon abundances among climate regimes, population abundances, and body sizes under varied lifehistory stages, from 1925 to 1998, using ordinary least squares and multivariate adaptive regression spline threshold models. The annual marine growth and body size during the juvenile, immature, and maturing life stages were estimated from growth pattern increments on the scales of adult age 2.2 sockeye salmon that returned to spawn at Karluk River and Lake on Kodiak Island, Alaska. Intra-specific density-dependent growth was inferred from inverse relationships between growth and sockeye salmon abundance based on commercial harvest. Density-dependent growth occurred in all marine life stages, during the cool regime, at lower abundance levels, and at smaller body sizes at the start of the juvenile life stage. The finding that density dependence occurred during the cool regime and at low population abundances suggests that a shift to a cool regime or extreme warm regime at higher population abundances could further reduce the marine growth of salmon and increase competition for resources.
\end{abstract}

KEY WORDS: Sockeye salmon - Marine growth · Density dependent $\cdot$ Ocean regimes $\cdot$ Climate change $\cdot$ Body size $\cdot$ Age

\section{Resale or republication not permitted without} written consent of the publisher

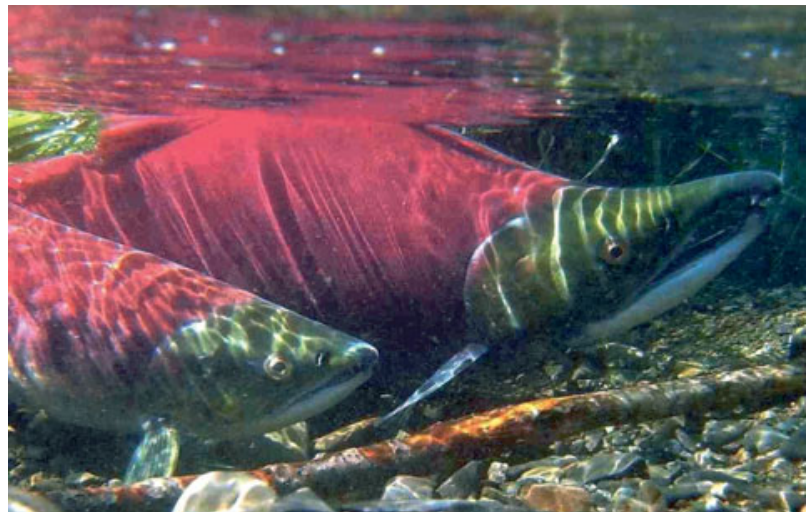

Growth patterns on the scales of maturing sockeye salmon record density-dependent and density-independent freshand saltwater conditions.

Photo: Masahide Kaeriyama

\section{INTRODUCTION}

In the last quarter of the 20th century, considerable research was conducted to assess the effects of climatic and oceanic variations on production and yield of salmonid fishes. Although studies earlier in the century had focused on dominant freshwater factors (Neave 1949, Shapovalov \& Taft 1954), the broad climatic and oceanic factors had been inadequately considered (Ricker 1976). In the later part of the century, yield and survival rates of Pacific salmon Oncorhynchus spp. 
were linked to fluctuations in regional climate and basin-scale variations in ocean conditions (Royal \& Tully 1961, Cushing 1971, Scarnecchia 1981, Beamish \& Bouillon 1993, Mueter et al. 2005). Climatic and oceanic variations have also been associated with fluctuations in Atlantic salmon Salmo salar abundance and catches in Iceland (Scarnecchia 1984, Scarnecchia et al. 1989), Ireland (Boylan \& Adams 2006), and Norway and Scotland (Friedland et al. 2000).

During the 20th century, climatic and oceanic conditions in the North Pacific have undergone large fluctuations, with 2 distinct warm regimes (1925 to 1946 and 1977 to 1998) and a cool regime (1947 to 1976) (Mantua \& Hare 2002). Warm regimes were characterized by a deepening and eastward shift in the Aleutian Low Pressure cell, increased winter storm activity, increased atmospheric circulation, below normal seasurface temperatures (SSTs), increased upwelling of nutrient-rich waters in the central North Pacific Ocean; above normal SSTs, higher precipitation, weaker downwelling in the coastal Gulf of Alaska; and weaker upwelling in coastal waters off the continental United States. The cool regime was characterized by the opposite conditions (Trenberth \& Hurrell 1994).

Climate and oceanic variations have been linked to concurrent variations in Pacific salmon production. Cool regimes, in part due to increased coastal upwelling of nutrient-rich, cooler waters, favor salmon production in Washington and Oregon (Scarnecchia 1981), whereas warm regimes favor salmon production in Alaska (Eggers et al. 2003). For example, Alaska salmon stocks fluctuated in phase with decadal scale fluctuations in North Pacific Ocean SSTs at a 1 yr lag for pink salmon Oncorhynchus gorbuscha and at 2 and 3 yr lags for sockeye salmon $O$. nerka, indicating that warming and water column stability during the first year at sea is important in determining survival (Mantua et al. 1997).

Shifts in non-salmonid dynamics also coincided with the 1976 to 1977 climatic and oceanic shift. Off the west coast of the continental United States, mackerel Scomber australasicus and chum salmon Oncorhynchus keta populations increased, while sockeye, pink, coho O. kisutch, and Chinook salmon O. tshawytscha, Pacific ocean perch Sebastes alutus, several rockfish species (Sebastes pinniger, S. paucispinis S. flavidus), dover sole Microstomus pacificus, sablefish Anoplopoma fimbria, and Greenland turbot Reinhardtius hippoglossoides populations declined (Hare \& Mantua 2000, Lees et al. 2006). In the Gulf of Alaska, species composition shifted from shrimp to salmonids and flatfish such as halibut Hippoglossus hippoglossus and arrowtooth flounder Atheresthes stomias (Hare \& Mantua 2000). In the Bering Sea, a reduction in the extent of sea-ice cover in the spring and zooplankton bio- mass coincided with a shift from benthic species such as Pacific ocean perch, yellowfin sole Limanda aspera, Greenland turbot, Alaska plaice Pleuronectes quadrituberculatus, Stellar sea lions Eumetopias jubatus, northern fur seals Callorhinus ursinus, and harbor seals Phoca vitulina to pelagic species such as jellyfish of the class Scyphozoa, walleye pollock Theragra chalcogramma, Pacific herring Clupea pallasii, and Pacific salmon (Manak \& Mysak 1987, Pitcher 1990, Trites 1992, Trites \& Larkin 1996, Brodeur et al. 1999, Hare \& Mantua 2000).

Several studies also support the notion that climatic and oceanic conditions can affect salmon-carrying capacity (Myers et al. 2001, Kaeriyama et al. 2007), manifested as density-dependent survival and growth responses to food resource limitations (Salo 1988, Fukuwaka \& Suzuki 2000). From the mid-1970s to the mid-1990s, increases in overall salmon production coincided with decreased growth, decreased size at maturity, and increased age at maturity of many North American salmon populations (Ishida et al. 1993, Helle \& Hoffman 1995, Bigler et al. 1996). An increase in ocean-carrying capacity in the 1990s was hypothesized, based on the observation of increases in the body size of salmon at maturity during high population levels from Oregon north to western Alaska (Helle et al. 2007). Climatic and oceanic variations can also potentially influence density-dependent competition by altering salmon distribution (Rogers 1980), changing the latitudinal boundary of the summer feeding zones (Aydin et al. 2000), and increasing overlap in the diets of sockeye, pink, chum, and coho salmon (Kaeriyama et al. 2004).

The potential for intra- and inter-specific competition among Pacific salmon stems from their high degree of overlap in distribution and feeding in the marine environment. Juvenile Pacific salmon are distributed across coastal continental shelf waters during the summer growing season (Myers et al. 1996). In the Central North Pacific Ocean, immature sockeye salmon from central and southern Alaska are distributed and feed with other salmon from North America and Asia (Kaeriyama et al. 2004). Maturing sockeye salmon from southern Alaska are distributed more eastward and feed primarily with immature and maturing salmon in offshore waters, and with juvenile salmon in coastal waters as they return to their natal streams to spawn (Myers et al. 1996, Kaeriyama et al. 2004).

We examined changes in the density-dependent growth of sockeye salmon in relation to climate regimes, population abundance, and body size by lifehistory stages, from the mid-1920s to the late 1990s, using linear and threshold modeling techniques. We hypothesized that the marine growth of sockeye 
salmon will relate inversely to the abundance of sockeye salmon, an indicator for density-dependent growth, at the higher population abundances associated with warm regimes. We correlated the increments of annual marine growth patterns on the scales of adult sockeye salmon Oncorhynchus nerka that returned to the Karluk River, Kodiak Island, Alaska, with the marine abundance of sockeye salmon (as indicated by harvest statistics) in central and southeast Alaska over a 74 yr period. Understanding factors that cause variation in density-dependent interactions among fish in the marine environment will provide insight into the influence of climate change on the carrying capacity for fishes in the North Pacific Ocean.

\section{MATERIALS AND METHODS}

Although direct fish length information was not available from salmon collected at sea, scales had been collected over the period from 1925 to 2000 (with $7 \mathrm{yr}$ of missing data: 1945, 1947, 1958, 1965, 1966, 1969, and 1979) from the age 2.2 sockeye Oncorhynchus nerka that returned to Karluk Lake on Kodiak Island, Alaska. Age was designated using the decimal method whereby the number to the left of the decimal is the number of winters spent in freshwater after emergence from the gravel and the number to the right of the decimal is the number of winters spent in saltwater (Koo 1962). For example, age 2.2 represented a 5 yr old fish. Marine growth was estimated indirectly from growth pattern measurements on the scale.

Scale samples and preparation. For each year, between 30 and 50 scales were selected at equal time intervals throughout the collection period from the early run (May 1 to July 21) spawning migration. From historical records, scales had been taken from the sockeye at a few rows above the lateral line and below the posterior insertion of the dorsal fin using a scrape (1925 to 1951) or forceps (1952 to 1998) method and assumed low variability in the body location sampled for scales among years (Clutter \& Whitesel 1956, Scarnecchia 1979). One scale per fish had been placed onto gummed cards with the reticulated side facing away from the card and impressed onto an acetate card using a hydraulic press at $100^{\circ} \mathrm{C}$ and 224 psi for 3 min (Arnold 1951).

Scale impressions were viewed and scanned using an Indus microfiche reader Model 4601-11 with a $24 \times$ objective lens. Images of scales were copied from the reader screen with the Screenscan Microfiche PC Model high-resolution scanner hardware and saved as tiff files using the ScreenScan Application software, Version 1.00.0.8. Images were then imported into the Optimate image analysis software for measuring.
Fish scale measurements. In using fish scale measurements to estimate marine growth of salmon, we assumed that: (1) growth along a specified radius of the scale was proportional to the growth in fish length (Dahl 1909) and (2) the distance between adjacent annuli on a scale depicted 1 yr of somatic growth (Fukuwaka \& Kaeriyama 1997).

Scales were read for age and measured by the senior author. Fish scale measurements $(\mathrm{mm})$ were taken along a consistent reference line drawn from the focus to the edge of the scale along the longest anterior radial axis (Narver 1968) to reduce variation in measurements among radial axes (Martinson et. al 2000). Measurements were adjusted to the original fish scale size by dividing by 24 . One scale was measured per fish for up to 50 scales $\mathrm{yr}^{-1}(\mathrm{~N}=69 \mathrm{yr})$ for a total of 3116 scales.

Growth during each year of marine residence was estimated from the measured distances between adjacent annuli on the fish scale image (Fig. 1). Smolt size or total freshwater growth (FW), an indicator for body length at the start of the first marine year as juveniles, was estimated as the distance from the center of the focus to the center of the space between the last freshwater circulus and the first marine circulus. Juvenile growth in the first marine year (M1) was estimated as the distance from the space between the last freshwater circulus and first marine circulus to the leading edge of the first marine annulus. Immature growth (M2) in the second marine year was estimated as the distance from the leading edge of the first marine annulus and the leading edge of the second marine annulus. Maturing growth (M3) in the third marine year was estimated as the distance from the leading edge of the second marine annulus to the outer edge of the scale. Scales with reabsorbed edges and evidence of being regenerated were not measured. Mean values for M1, M2, and M3 growth were calculated for each brood. Mean growth for the $7 \mathrm{yr}$ of missing scale data was estimated as points along a local ordinary leastsquared smoothing line fit to the data to satisfy the statistical analysis requirement of a complete time series. Because body size at the start of the growing season may influence growth, we also calculated mean values for the scale radius at the start of the juvenile $\left(\mathrm{FW}_{t}\right)$, immature $\left(\mathrm{L} 1_{t}=\mathrm{FW}_{t-1}+\mathrm{M} 1_{t-1}\right)$, and maturing (L2 $2_{t}=$ $\mathrm{FW}_{t-2}+\mathrm{M} 1_{t-2}+\mathrm{M} 2_{t-1}$ ) life stages. Mean values of specified scale growth measurements were calculated by brood year and compared among broods to assess inter-annual variation in growth by age group and stock.

Salmon abundance estimates. Information on salmon biomass was unavailable, as was information on the abundance, biomass, or catch per unit effort of juvenile, immature, and maturing salmon in the ocean. 


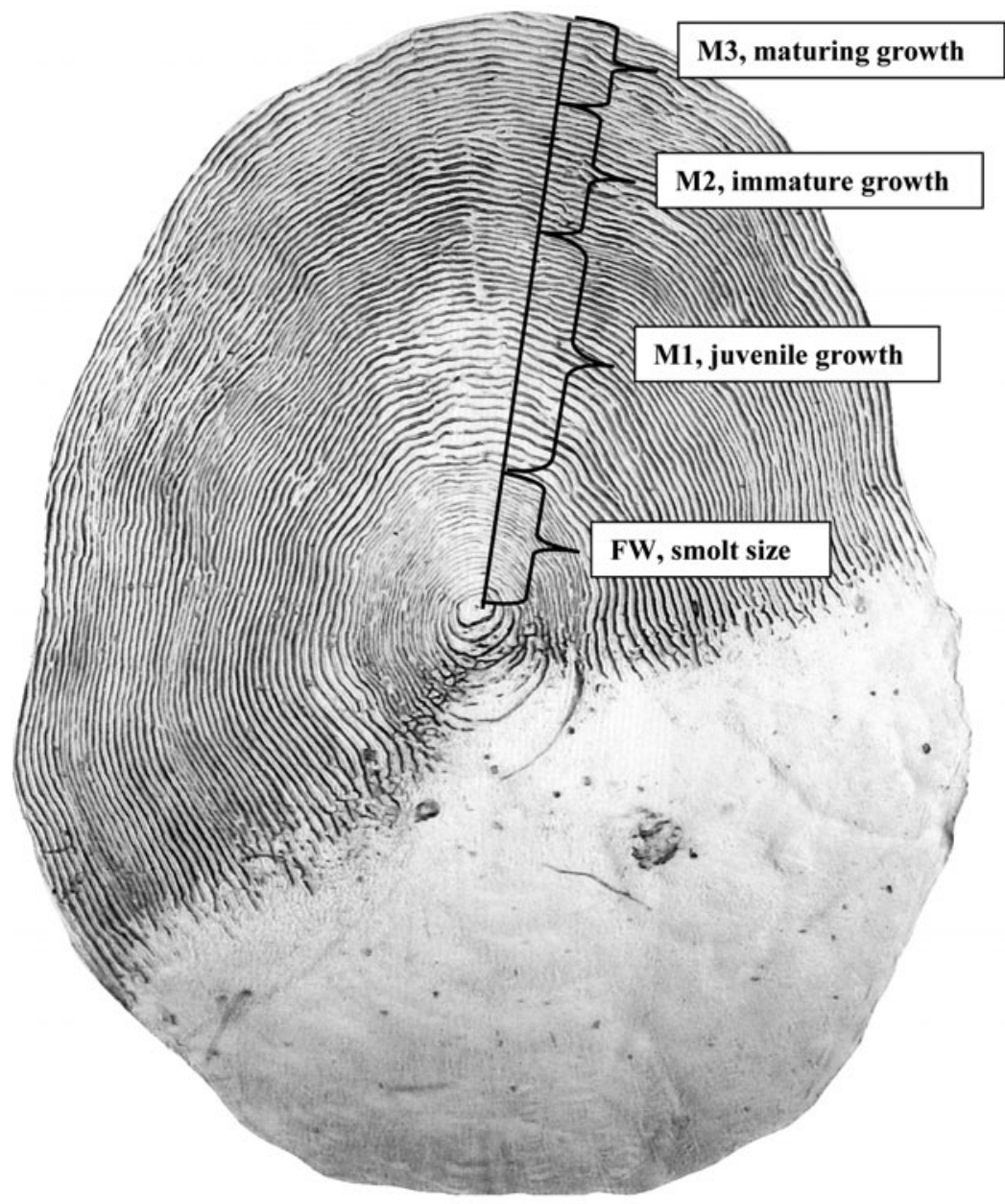

Fig. 1. Oncorhynchus nerka. Scale from an age 2.2 sockeye salmon from Karluk Lake, Alaska, showing the measurements for growth of the smolt (FW), juvenile (M1), immature (M2), and maturing (M3) stages

Therefore, the index of sockeye salmon abundance (SSA index) by cohort was based on estimates of commercial harvest (number of fish per year) in central and southeast Alaska management regions (Eggers et al. 2003). The central Alaska region included areas from Cape Suckling to Unimak Pass; the southeast Alaska region included areas from British Columbia to Cape Suckling. In using commercial harvest to estimate salmon abundance, we could not account for interannual variation in exploitation rate, management, marine mortality rates, or sport and subsistence fisheries.

Marine growth versus salmon abundance. It was hypothesized that intra-specific density-dependent growth would be manifested as negative relationships between the estimated marine growth based on fish scale measurements (M1 to M3) and the SSA index lagged to the growth year of the cohort. Juvenile growth (M1) in year $t$ was related to the number of maturing sockeye salmon caught in the fishery in year $t+2$ (SSAM1), the abundance index for the juvenile sockeye in year $t$. Immature growth (M2) in year $t$ was related to the number of maturing sockeye captured in the fishery in year $t+1$ (SSAM2), the abundance index for immature sockeye salmon in year $t$. Maturing growth (M3) in year $t$ was related to the number of maturing sockeye captured in the fishery in year $t$ (SSAM3), the abundance index for maturing sockeye salmon in year $t$. Means, standard deviation, and range of growth and abundance variables are summarized in Table 1.

Two-way scatter plots and line plots between scale growth (dependent variable) and sockeye salmon abundance indices (independent variable) were created for M1 versus SSAM1, M2 versus SSAM2, and M3 versus SSAM3 (Figs. 2 \& 3). Plots were examined for negative growth-abundance relationships and changes in relationships associated with the 3 North Pacific Ocean climatic and oceanic regimes (i.e. early warm [1925 to 1946], cool [1947 to 1976], and the late warm [1977 to 1998] regimes). Climate-oceanic regime was included as a categorical variable (called SHIFT) in the models to test whether a change occurred in the growth-abundance relationship associated with the regime shift. To verify the presence of the regime shift we substituted YEAR for SHIFT and allowed the model to automatically detect changes in the relationships between growth and predictor variables.

Statistical analyses. To describe density-dependent growth of Karluk sockeye salmon during each marine life-history stage we used 2 statistical methods: ordinary least squares (OLS) and multivariate adaptive regression spline (MARS) (Friedman 1991, Lewis \& Stevens 1991). First, the relationship between fish scale growth and population abundance was explored for each regime using the OLS model. Then, in both methods, individual models for the growth of the fish as juvenile (M1), immature (M2), and maturing (M3) individuals were described as a function of: (1) the 1976 to 1977 ocean regime shift (SHIFT), (2) the growth at lag year 1 (M1\{1\}, M2\{1\}, M3\{1\}) and growth at lag year 2 (M1\{2\}, M2\{2\}, M3\{2\}), (3) body length at the start of the growing season (FW, L1, L2), and (4) the sockeye salmon abundance index (SSAM1, SSAM2, SSAM3) (Table 1). Growth at lag years 1 and 2 may represent environmental variation, unknown processes, 
Table 1. Oncorhynchus nerka. Means, standard deviations (SD), maximum (Max), and minimum (Min) values for fish scale growth (M1, M2, M3 [mm], see Fig. 1), body size at the start of the juvenile year (FW, mm), immature year (L1, mm), and maturing year (L2, mm), and sockeye salmon abundance indices (SSAM1, SSAM2, SSAM3) and the 1976 to 1977 regime shift (SHIFT)

\begin{tabular}{|c|c|c|c|c|c|}
\hline Variable & Description & Mean & $\mathrm{SD}$ & Max & Min \\
\hline $\mathrm{FW}\{0\}$ & Total smolt length; aligned with $\mathrm{M} 1\{0\}$ & 0.6533 & 0.0537 & 0.8085 & 0.5646 \\
\hline M1 & 1st year marine juvenile growth & 1.0600 & 0.0609 & 1.1958 & 0.9165 \\
\hline SSAM1 & Southern Alaska sockeye index; aligned with M1 & 8.3266 & 4.7978 & 22.700 & 2.2000 \\
\hline L1 $\{0\}$ & $\mathrm{FW}\{1\}+\mathrm{M} 1\{1\} ;$ aligned with $\mathrm{M} 2\{0\}$ & 1.7139 & 0.0568 & 1.9345 & 1.5529 \\
\hline M2 & 2nd year marine immature growth & 0.7771 & 0.0675 & 0.9458 & 0.6279 \\
\hline SSAM2 & Southern Alaska sockeye index; aligned with M2 & 8.3014 & 4.7784 & 22.700 & 2.2000 \\
\hline $\mathrm{L} 2\{0\}$ & $F W\{2\}+M 1\{2\}+M 2\{1\} ;$ aligned with $M 3\{0\}$ & 2.4891 & 0.1079 & 2.7505 & 2.2281 \\
\hline M3 & 3rd year marine maturing growth & 0.3346 & 0.0530 & 0.4550 & 0.2450 \\
\hline SSAM3 & Southern Alaska sockeye index; aligned with M3 & 8.1622 & 4.6673 & 22.700 & 2.2000 \\
\hline SHIFT & 0 from $1925-1976 ; 1$ from $1977-1998$ & 0.2973 & 0.4602 & 1.0000 & 0.0000 \\
\hline
\end{tabular}

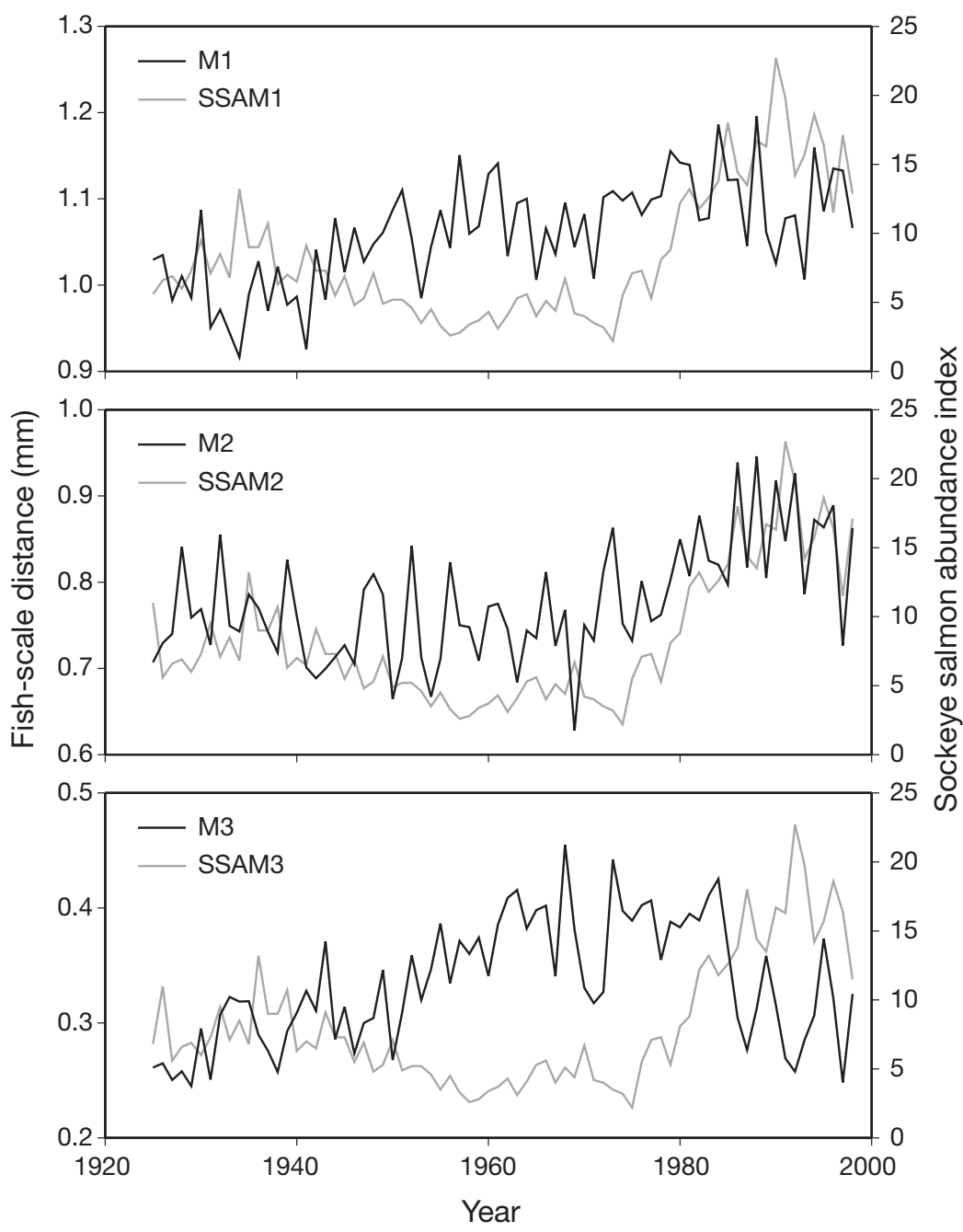

Fig. 2. Oncorhynchus nerka. Trends in the mean annual juvenile (M1), immature (M2), and maturing (M3) marine growth of the age 2.2 sockeye salmon (based on fish scale measurements) returning to Karluk Lake, Alaska, in relation to the index for the abundance of juvenile (SSAM1), immature (SSAM2), and maturing (SSAM3) of sockeye salmon from central and southeast Alaska, 1925 to 1998 and/or an interaction with a species having a 2 yr abundance cycle (Ruggerone et al. 2003). Density-dependence was inferred from negative relationships between growth and population abundance.

The OLS model $y=\hat{f}\left(x_{1}, x_{2}, \ldots, x_{k}\right)$, where $y$ was the dependent variable and $x_{i}, i=1, \ldots, k$ were the independent variables, assumed that all relationships are linear and that all variables are in the model for every period. The estimated coefficient for the $i$ th input variable $x_{i}$ in a model $y=\hat{\beta}_{0}+\hat{\beta}_{1} x_{1}+\hat{\beta}_{k} x_{k}$ $+\ldots+\hat{\beta}_{k} x_{k}+e$ measured the unit change of that input variable in explaining a change in the dependent variable $y$ and whether the input variable was positively related or negatively related to the dependent variable. The statistical significance of the estimated coefficient was measured using the $t$-value $\hat{\beta}_{k} / \mathrm{SE}$ $\left(\hat{\beta}_{k}\right)$. Values $>1.7$ were considered significant. Some important restrictions of OLS include: (1) that the relationship, if found, was always present; (2) the relationship was always the same size for a 1 unit change in the independent variable; and (3) unless the independent variable was transformed it was not related to other independent variables.

The MARS technique allowed testing and relaxing of the restrictive assumptions of the OLS method. The MARS model $y=f(x)$ allowed the possibility that the relationship of $x$ on $y$ could be impacted by an unknown threshold $\tau^{*}$ which alters the relationship (Friedman 

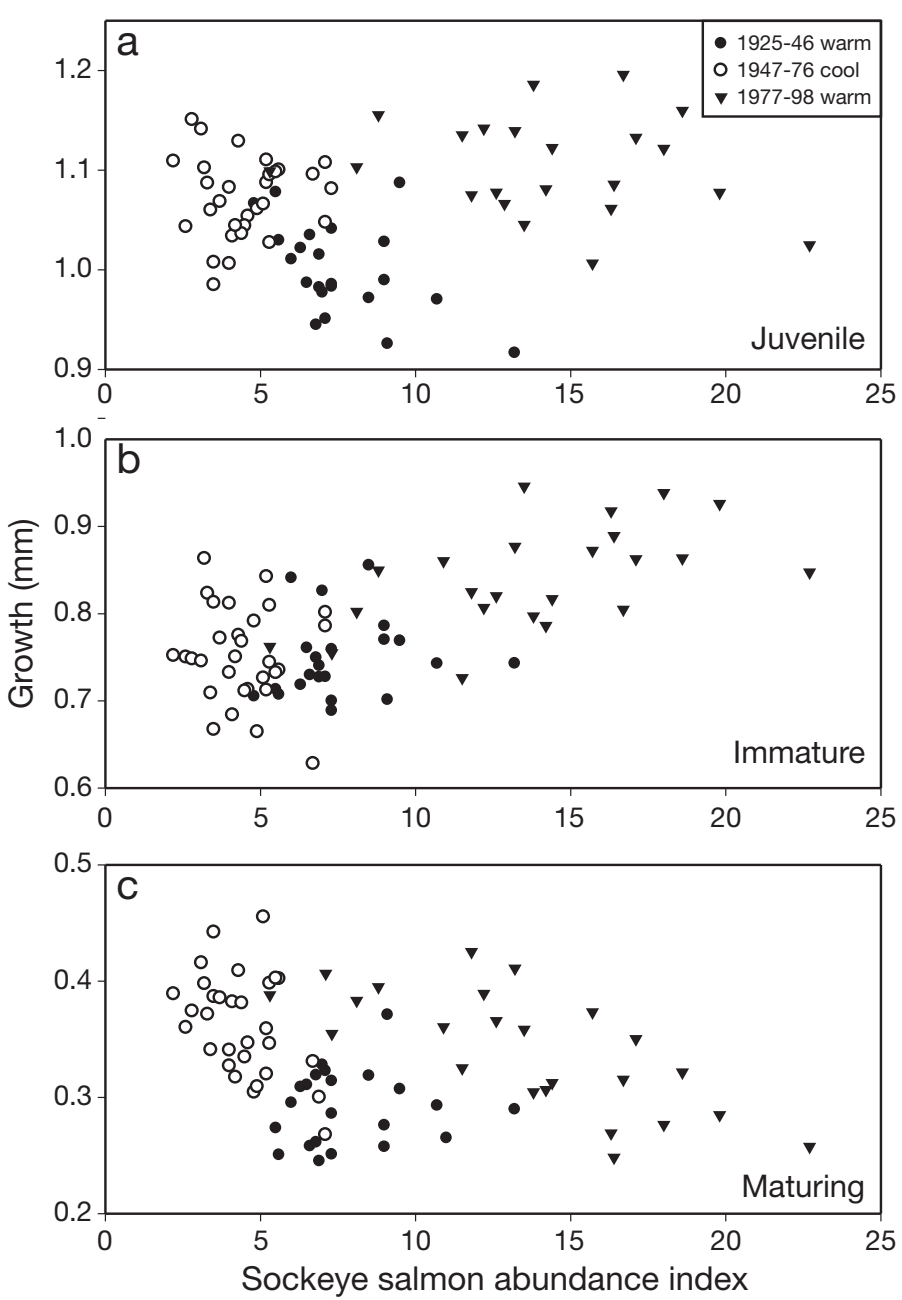

Fig. 3. Oncorhynchus nerka. Ocean-regime comparison of the relationships between the mean annual marine growth of age 2.2 Karluk Lake sockeye salmon for: (a) the juvenile growth (M1) and the juvenile sockeye abundance index (SSAM1), (b) immature growth (M2) and immature sockeye abundance index (SSAM2), and (c) maturing growth (M3) and the maturing sockeye abundance index (SSAM3) in 3 ocean regimes, 1925 to 1998: 1925 to 1946 warm (•), 1947 to $1976 \mathrm{cool}(\mathrm{O})$, and 1977 to 1998 warm (v)

1991, Lewis \& Stevens 1991). For example, for a threshold value of 100, 2 expressions may apply:

$$
\begin{array}{ll}
y=\alpha+\beta_{1} x+e & \text { for } x>100 \\
y=\alpha+\beta_{2} x+e & \text { for } x<100
\end{array}
$$

In terms of the MARS notation, Eq. (1) can be written as:

$$
y=\alpha^{\prime}+C_{1}\left(x-\tau^{*}\right)_{+}-C_{2}\left(\tau^{*}-x\right)_{+}+e
$$

where $e$ is the residual of the model, $\tau^{*}=100$ in the population but is estimated by MARS for the sample. The term ()$_{+}$is the right $(+)$truncated spline function, which takes the value 0 if the expression inside ()$_{+}$is less than or equal to zero and its actual value if the expression inside ()$_{+}$is $>0$. Here $c_{1} \equiv \beta_{1}$ and $c_{2} \equiv \beta_{2}$. Once the transformed vectors $\left[\left(x-\tau^{*}\right)_{+}\right.$, and $\left.\left(\tau^{*}-x\right)_{+}\right]$in Eq. (2) are determined, OLS is used to solve for the coefficients $\left(\alpha_{1}, c_{1}, c_{2}\right)$ (Stokes 1997, Stokes \& Lattyak 2006).

The MARS modeling technique was used to determine at what thresholds of the predictor variables that correspond with changes in the relationship between growth and abundance. The model was expressed as:

$$
y=\alpha+C_{1}\left(x-\tau_{1}^{*}\right)_{+}-C_{2}\left(\tau_{1}^{*}-x\right)_{+}+C_{3}\left(x-\tau_{1}^{*}\right)_{+}\left(z-\tau_{2}^{*}\right)_{+}+e
$$

The model was interpreted as 3 nested models depending on the values of $x$ and $z$ as follows:

$$
\begin{aligned}
y= & \alpha+c_{1} x-c_{1} \tau_{1}^{*}+e & & \text { for } x>\tau_{1}^{*} \text { and } z<\tau_{2}^{*} \\
= & \alpha-c_{2} x+c_{2} \tau_{1}^{*}+e & & \text { for } x<\tau_{1}^{*} \\
= & \alpha+c_{1} x-c_{1} \tau_{1}^{*}+ & & \\
& c_{3}\left(x z-\tau_{1}^{*} z-\tau_{2}^{*} x+\tau_{1}^{*} \tau_{2}^{*}\right)+e & & \text { for } x>\tau_{1}^{*} \text { and } z>\tau_{2}^{*}
\end{aligned}
$$

Model results reported as $\left(x_{i}-\tau_{i}^{*}\right)_{+}$and $\left(\tau_{i}^{*}-x_{i}\right)$ were displayed as $\max [(x-c), 0.0]$ and $\max [(c-x), 0.0]$, respectively, where $c=\tau^{*}$. For example, a model $y=c(x-3.0)_{+}$indicated that if $x \leq 3.0, y=0$. For cases $x>3.0, y=c x-3 c$.

OLS models are the usual way that an analysis such as this might be attempted. OLS represents a good 'first cut' at modeling a relationship, but makes a number of assumptions that can profitably be investigated. The first and foremost assumption is the linearity of the coefficients. A model $y=a+b \times x+e$ assumes that no matter what the level of $x$, the relationship remains fixed. MARS models include OLS models as special cases but allow the OLS model assumptions to be relaxed in a number of ways. First, MARS models can detect and estimate thresholds. Variables may not impact the left-hand side if they are above or below an estimated value to be determined by the model. By graphing when the right-hand-side variables play a role in the prediction of $y$ by time, as we later show, we can obtain interesting insight into the dynamics of a timeseries relationship that is hidden inside the OLS model specification. MARS models are of the shrinkage class, in that variables may not stay in the analysis or might be found to only enter as interaction terms. To see the gains from MARS models it is first important to estimate and report OLS models to serve as a base case.

To show the exact years in which the dependent variables added to the prediction of the growth variables $y$ (M1, M2, M3), we presented line plots of the transformed vectors. For each plot, the effect of the predictor variables on M1, M2, and M3 growth in millimeters was interpreted as the coefficient of the model multiplied by the value on the $y$-axis. The direction of 
the relationship between the predictor and dependent variable was interpreted as the product of signs of the coefficient and the value. Finally, the overall MARS model results for the relationship between marine growth and sockeye salmon abundance were plotted to examine the overall density-dependent relationship. Three-dimensional plots were used to represent the growth-abundance term with 1 interaction variable and other variables held constant.

For MARS estimation, the B34S Software Version 8.11D, which uses the GPL MarsSpline software library developed by Hastie \& Tribshirani $(1986,1990)$ for R, was employed. Stokes (1997) is a basic published reference for B34S, and in Chapter 14 it covers MARS estimation in some detail. The MarsSpline GPL library, distributed with $\mathrm{R}$, is distinct from and is an alternative to the proprietary MARS software initially developed by Friedman (1991). A number of figures were produced using the RATS Version 7.0 software developed by Estima (Doan 2007a,b).

\section{RESULTS}

Inspection of Figs. 2 \& 3 suggested that marine growth as indicated by fish scale measurements was negatively and positively related to the sockeye salmon abundance index. Three clusters in the growth-abundance relationships of Oncorhynchus nerka were observed, but the strongest separation was at the 1976 to 1977 climateoceanic regime shift (Fig. 3). M1 declined for the combined 1925 to 1946 and 1947 to 1976 regimes as sockeye salmon abundance increased from 2 million to 10 million, and was high as sockeye salmon abundances increased for the 1977 to 1998 regime (Fig. 3a). M2 was not related to SSAM2 prior to 1977 , but M2 increased as SSAM2 increased for the 1977 to 1998 regime (Fig. 3b). M3 showed a similar pattern as M1 (Fig. 3c).
These general visual impressions were tested statistically using simplified OLS models (Table 2). The coefficient for SSAM1 for the M1 model in the 1925 to 1946 regime was negative $(-0.0117)$ and significant $(t=$ -2.48), supporting our contention that M1 declined in the early warm regime. In the cool 1947 to 1976 regime, the coefficient was not significant. However, for the longer period from 1925 to 1976, the coefficient was more negative $(-0.0146)$ and significant $(t=-5.05)$ compared to that from 1925 to 1946 . For the M2 models, only in the later 1977 to 1998 regime was the coefficient $(0.0083)$ significant $(t=3.21)$. For the M3 models, the slope was not significant for the 1925 to 1946 regime, but was significant $(-0.152)$ and negative $(t=$ -2.48 ) in the 1947 to 1976 cool regime. When we combined the data, the 1925 to 1976 period was more significant (coefficient $=-0.1036)$ and negative $(t=-5.17)$ than the cool regime alone. For the 1977 to 1998 regime, the coefficient was also negative $(-0.0089)$ and significant $(t=-4.80)$.

It should be stressed that the simple OLS models are only to be used to summarize the graphs in a statistical sense (Table 2). These support our contention in breaking the analysis into 2 specific regimes (1925 to 1976 and 1977 to 1998) rather than attempting a 3 regime model. Evidence for this model parameterization is contained in the MARS models.

\section{Juvenile growth models}

\section{OLS model}

Juvenile growth (M1) was negatively associated with the juvenile sockeye salmon abundance index (SSAM1), and positively associated with the 1976 to 1977 regime shift and M1 at lag yr $2(\mathrm{SSR}=0.157)$ in the OLS model (Table 3). Non-significant variables in-

Table 2. Oncorhynchus nerka. Ordinary least squared (OLS) regression model coefficients (Coeff.) and standard error, and $t$-values used to describe the mean annual marine growth as indicated by fish scale measurements (M1, M2, M3) of age 2.2 sockeye that returned to Karluk Lake, Alaska, as a function of the sockeye salmon abundance indices (SSAM1, SSAM2, SSAM3) from 1925 to 1998. Asterisks indicate a $5 \%$ significance level for $t$-values $>1.7$. C represent the CONSTANT in the OLS model

\begin{tabular}{|c|c|c|c|c|c|c|c|c|c|c|c|c|}
\hline \multirow[t]{2}{*}{ Model } & & & & & & \multicolumn{4}{|c|}{ Ocean regimes } & \multirow{2}{*}{\multicolumn{2}{|c|}{$\begin{array}{lc} & 1977-98 \\
\text { Coeff. } & \text { SE }\end{array}$}} & \multirow[b]{2}{*}{$t$} \\
\hline & Coeff. & $\begin{array}{c}1925-46 \\
\mathrm{SE}\end{array}$ & - & Coeff. & $\begin{array}{c}1947-76 \\
\text { SE }\end{array}$ & $\bar{t}$ & $\overline{\text { Coeff. }}$ & $\begin{array}{c}1925-76 \\
\text { SE }\end{array}$ & $\bar{t}$ & & & \\
\hline \multicolumn{13}{|l|}{ M1 } \\
\hline SSAM1 & $-0.0117^{*}$ & 0.0047 & -2.48 & 0.0013 & 0.0056 & 0.23 & $-0.0146^{*}$ & 0.0029 & -5.05 & -0.0022 & 0.0027 & -0.79 \\
\hline $\mathrm{C}$ & 1.0885 & 0.0368 & 29.54 & 1.0660 & 0.0265 & 40.16 & 1.1264 & 0.0180 & 62.50 & 1.1351 & 0.0405 & 27.99 \\
\hline \multicolumn{13}{|l|}{ M2 } \\
\hline SSAM2 & -0.0022 & 0.0052 & -0.43 & -0.0048 & 0.0082 & -0.58 & -0.0021 & 0.0031 & -0.67 & $0.0083^{*}$ & 0.0026 & 3.21 \\
\hline $\mathrm{C}$ & 0.7655 & 0.0425 & 18.03 & 0.7732 & 0.0378 & 20.44 & 0.7623 & 0.0194 & 39.27 & 0.7245 & 0.0376 & 9.19 \\
\hline \multicolumn{13}{|l|}{ M3 } \\
\hline SSAM3 & 0.0015 & 0.0037 & 0.41 & $-0.0152^{*}$ & 0.0061 & -2.48 & $-0.0136^{*}$ & 0.0026 & -5.17 & $-0.0089^{*}$ & 0.0018 & -4.80 \\
\hline $\mathrm{C}$ & 0.2790 & 0.0297 & 9.38 & 0.4303 & 0.0280 & 15.35 & 0.4123 & 0.0166 & 24.91 & 0.4597 & 0.0262 & 17.51 \\
\hline
\end{tabular}


Table 3. Oncorhynchus nerka. Ordinary least squared regression model coefficients and results used to describe the mean annual marine growth as indicated by fish scale measurements of age 2.2 sockeye that returned to Karluk Lake, Alaska, as a function of the 1976-77 ocean regime shift, autocorrelation in growth, mean cumulative cohort scale growth, and sockeye salmon abundance indices from 1925 to 1998. ${ }^{*} 5 \%$ significance level for $t$-values $>1$.7. SHIFT is a categorical variable, whereby 0 is years from 1925 to 1976 and 1 is years from 1977 to 1998 . Response variables include mean scale growth in the first marine year (M1), second marine year (M2), and third marine year (M3). SASM1, SASM2, and SASM3 are southern Alaska sockeye aligned with the appropriate series. $\mathrm{L} 1\{0\}=\mathrm{FW}\{1)+\mathrm{M} 1\{1)$, where \{\} refers to the lag. $\mathrm{L} 2\{0\}=\mathrm{FW}\{1\}+\mathrm{M} 1\{1\}$. FW: total body length in freshwater. Each equation has 72 observations. The $\mathrm{R}^{2}$ and residual sum of squares for the M1, M2, M3 models were, respectively, 0.371 and $0.157,0.373$ and 0.188 , and 0.611 and 0.087

\begin{tabular}{|lrrrr|}
\hline Variable & Lag & Coefficient & SE & $t$-value \\
\hline M1 model & & & & \\
SHIFT & 0 & 0.0793 & 0.0278 & $2.85^{*}$ \\
M1 & 1 & 0.1055 & 0.1187 & 0.89 \\
M1 & 2 & 0.2860 & 0.1167 & $2.45^{*}$ \\
FW & 0 & -0.0265 & 0.1088 & -0.24 \\
SSSAM1 & 0 & -0.0050 & 0.0022 & $-2.22^{*}$ \\
CONSTANT & 0 & 0.6812 & 0.1826 & $3.73^{*}$ \\
M2 model & & & & \\
SHIFT & 0 & 0.0526 & 0.0254 & $2.08^{*}$ \\
M2 & 1 & -0.0951 & 0.1209 & -0.79 \\
M2 & 2 & 0.0317 & 0.1218 & 0.26 \\
L1 & 0 & 0.0485 & 0.0876 & 0.55 \\
SSAM2 & 0 & 0.0048 & 0.2260 & $2.14^{*}$ \\
CONSTANT & 0 & 0.6887 & 0.1950 & $3.53^{*}$ \\
M3 model & & & & \\
SHIFT & 0 & 0.0488 & 0.0181 & $2.70^{*}$ \\
M3 & 1 & 0.3989 & 0.1194 & $3.34^{*}$ \\
M3 & 2 & 0.1334 & 0.1147 & 1.16 \\
L2 & 0 & -0.0364 & 0.0499 & -0.73 \\
SSAM3 & 0 & -0.0059 & 0.0017 & $-3.52^{*}$ \\
CONSTANT & 0 & 0.2819 & 0.1255 & $2.25^{*}$ \\
\hline
\end{tabular}

cluded M1 at lag yr 1 and smolt size (FW) (Table 3). The model explained $37 \%$ of the variation in M1.

\section{MARS model}

Juvenile growth (M1) was significantly related to juvenile sockeye abundance (SSAM1), smolt size (FW), and M1 at lag yr 1 and 2 (M1\{1\}, M1\{2\}), but not to the 1976 to 1977 regime shift (Table 4). In comparison to the OLS model, the sum of squares was reduced from 0.157 to 0.114 and the MARS model explained an additional $21 \%$ of the variation in $\mathrm{M} 1\left(\mathrm{R}^{2}=0.58\right)$ (Table 5$)$. Unlike OLS, where all vectors are constant and active in the equation over the time, for the MARS model the number of active vectors was from 1 to 6 and the variables varied over time in the equation (Fig. 4). M1 was more related to predictors from 1925 to 1973 than from 1974 to 1998. Replacing YEAR for SHIFT resulted in no significant change in the M1 versus SSAM1 relationship over time, but did result in a positive shift in M1 in 1980.

The activity and magnitude of the effect of the predictors on growth varied over time (Figs. 5 to 7). During the early warm regime and in odd-numbered years, M1 was reduced $(t=-6.19)$ when M1 at lag yr 2, M1 $\{2\}$, decreased below the threshold of $1.078 \mathrm{~mm}$ (Fig. 5a). During the cool regime, M1 increased $(t=2.19)$ due to a decrease in M1\{2\} and/or a decrease in SSAM1 below 6.0 million, and was strongest in 1955, 1958, 1967, 1969, 1971, and 1973 (Fig. 5b). From 1925 to 1940, M1 was reduced $(t=-3.20)$ when M1\{2\} was decreasing below 1.078 and smolts were large $(\mathrm{FW}>0.659)$ (Fig. 5c). During the early warm regime, M1 $(t=3.64)$ increased when M1 at lag yr 1 and 2 were decreasing from average to below average in 1928, 1930, 1932 to 1935, 1938, 1940 to 1944, and 1954 (Fig. 5d). During the same period, and to a lesser magnitude, M1 was reduced $(t=-3.39)$ when M1 at lag yr 1 was decreasing M1 $\{1\} \leq 1.015$ (Fig. 5e). During the cool regime, M1 decreased when smolts (FW) were small and decreasing, and SSAM1 decreased below 4.9 in 1953, 1956, 1962, 1971, and 1972 (Fig. 5f).

\section{Immature growth models}

\section{OLS model}

Immature growth (M2) was positively associated with the 1976 to 1977 regime shift and the immature sockeye salmon abundance index (SSAM2), but not related to the growth lags (M2\{1\}, M2\{2\}) or size at the start of the immature growing season (L1) (Table 3). The predictors explained $38 \%$ of the variation in M2 with a sum of squares $=0.188$ (Table 3 ).

\section{MARS model}

In the MARS model, immature growth was significantly related to the 1976-77 regime shift (SHIFT), immature sockeye salmon abundance index (SSAM2), growth at lag yr 1 (M2\{1\}, growth at lag yr 2 (M1\{2\}) and size at the start of the growing season (L1) (Table 4). When a MARS model was estimated, the sum of squares fell to 0.144 and the additional variables, length at the start of the growing season (L1) and M2 at lag yr 1 and 2, entered into the model (Table 4). The MARS model explained an additional $18 \%$ of the variation in $\mathrm{M} 2\left(\mathrm{R}^{2}=0.556\right)$ compared to the OLS model. In $29 \mathrm{yr}$, mostly during the 1947 to 1976 cool regime, M2 increased $(t=2.54)$ as SSAM2 de- 
Table 4. Oncorhynchus nerka. Significant multivariate adaptive regression spline model coefficients and significant results used to describe the mean annual marine scale growth of age 2.2 sockeye that returned to Karluk Lake, Alaska, as a function of the 1976 to 1977 ocean regime shift; autocorrelation in growth, mean cumulative cohort scale growth, and sockeye salmon abundance indices from 1925 to $1998 . \mathrm{No}_{\mathrm{V}}=$ the number of times the variable enters into the model, or the number of years that the model component is active and having an affect on $\mathrm{M} 1, \mathrm{M} 2, \mathrm{M} 3 \mathrm{No}_{\mathrm{C}}=$ number of model components

\begin{tabular}{|c|c|c|c|c|c|c|}
\hline \multirow[t]{2}{*}{ Coefficients and thresholds } & \multirow[t]{2}{*}{$\mathrm{SE}$} & \multirow[t]{2}{*}{$t$-value } & \multicolumn{4}{|c|}{ Non-zero importance vector } \\
\hline & & & $\mathrm{No}_{V}$ & Percent & Rank & $\mathrm{No}_{\mathrm{C}}$ \\
\hline M1 = 1.1002 & 0.0070 & 157.00 & 72 & 100 & - & 1 \\
\hline$-0.9318 \times \max (1.0775-\mathrm{M} 1\{2\}, 0.0)$ & 0.1504 & -6.19 & 41 & 56 & 100.0 & 2 \\
\hline$+0.2403 \times \max (1.0775-\mathrm{M} 1\{2\}, 0.0) \times \max (6.0000-\mathrm{SSAM} 1\{0\}, 0.0)$ & 0.1093 & 2.19 & 1 & 22 & 35.5 & 3 \\
\hline$-9.1506 \times \max (1.0775-\mathrm{M} 1\{2\}, 0.0) \times \max (\mathrm{FW}\{0\}-0.6586,0.0)$ & 2.8562 & -3.20 & 16 & 22 & 51.7 & 4 \\
\hline$+21.9580 \times \max (1.0150-\mathrm{M} 1\{1\}, 0.0) \times \max (1.0775-\mathrm{M} 1\{2\}, 0.0)$ & 6.0235 & 3.64 & 13 & 18 & 58.8 & 5 \\
\hline$-1.7161 \times \max (1.0150-\mathrm{M} 1\{1\}, 0.0)$ & 0.5057 & -3.39 & 17 & 23 & 54.8 & 6 \\
\hline$-1.2290 \times \max (0.6210-\mathrm{FW}\{0\}, 0.0) \times \max (4.9000-\mathrm{SSAM} 1\{0\}, 0.0)$ & 0.3901 & -3.15 & 9 & 12 & 50.9 & 7 \\
\hline $\mathrm{M} 2=0.7301$ & 0.0109 & 67.20 & 72 & 100 & - & 1 \\
\hline$+0.01663 \times \max (6.0000-\mathrm{SSAM} 2\{0\}, 0.0)$ & 0.6530 & 2.54 & 29 & 40 & 59.5 & 2 \\
\hline$+0.04354 \times \max (\operatorname{SHIFT}\{0\}-0.0000,0.0)$ & 0.2019 & 2.1 & 22 & 30 & 50.3 & 3 \\
\hline$+0.01005 \times \max (\operatorname{SSAM} 2\{0\}-4.6000,0.0)$ & 0.2346 & 4.28 & 54 & 75 & 100.0 & 4 \\
\hline$-0.6231 \times \max (\mathrm{M} 2\{1\}-0.8202,0.0)$ & 0.2007 & -3.10 & 24 & 33 & 72.5 & 5 \\
\hline$-7.5709 \times \max (0.8202-\mathrm{M} 2\{1\}, 0.0) \times \max (1.6626-\mathrm{L} 1\{0\}, 0.0)$ & 2.4894 & -3.04 & 14 & 19 & 71.0 & 6 \\
\hline $\mathrm{M} 3=0.2862$ & 0.7198 & 39.70 & 72 & 100 & - & 1 \\
\hline$+1.4818 \times \max (\mathrm{M} 3\{1\}-0.3461,0.0)$ & 0.2404 & 6.16 & 30 & 41 & 100.0 & 2 \\
\hline$+0.01352 \times \max (6.8000-\operatorname{SSAM} 3\{0\}, 0.0)$ & 0.3067 & 4.40 & 35 & 48 & 71.5 & 3 \\
\hline$-64.5434 \times \max (\mathrm{M} 3\{1\}-0.3461,0.0) \times \max (\mathrm{M} 3\{2\}-0.3819,0.0)$ & 14.3292 & -4.50 & 16 & 22 & 73.1 & 4 \\
\hline$+1.9227 \times \max (\mathrm{M} 3\{2\}-0.3658,0.0)$ & 0.4603 & 4.17 & 24 & 33 & 67.8 & 5 \\
\hline$-58.7729 \times \max (\mathrm{M} 3\{1\}-0.3269,0.0) \times \max (0.3658-\mathrm{M} 3\{2\}, 0.0)$ & 14.3066 & -4.10 & 14 & 19 & 66.6 & 6 \\
\hline$+29.8197 \times \max (\mathrm{M} 3\{1\}-0.2951,0.0) \times \max (0.3658-\mathrm{M} 3\{2\}, 0.0)$ & 8.3421 & 3.57 & 30 & 41 & 58.0 & 7 \\
\hline
\end{tabular}

creased below a threshold of 6.0 million (Fig. 6a). At the time of the 1976 to 1977 regime shift, there was a $5.7 \%$ significant $(t=2.15)$ increase in M2 (Fig. 6b). M2 was most significantly increased $(t=4.28)$ as SSAM2 increased above 4.6 million in 54 yr during warm regimes and was twice as strong in 1977 to 1998 warm regime than the 1925 to 1946 warm regime (Fig. 6c). In odd-numbered years during the late warm regime, M2 growth was reduced $(t=-3.10)$ as M2 at lag yr 1 was high and increasing above $0.8208 \mathrm{~mm}$ (Fig. 6d). In $1942,1954,1963$, and 1972, M2 was reduced $(t=$ -3.04), as M2 at lag yr 1 decreased and/or the size at the start of the growing season (L1) decreased below a smaller threshold size (1.663 mm) (Fig. 6e). Replacing YEAR for SHIFT resulted in a significant change to a positive M2 versus SSAM2 relationship in 1968 and a weak change to a negative relationship in 1980. Shifts in M2 occurred in $1950(-)$ and 1956 (+).

Table 5. Multivariate adaptive regression spline model results for models in Table 4

\begin{tabular}{|lccc|}
\hline & \multicolumn{3}{c|}{ Model } \\
\cline { 2 - 4 } & M1 & M2 & M3 \\
\hline $\mathrm{R}^{2}=\{1-[\operatorname{var}($ res $) /$ var(y)] $\}$ & 0.576 & 0.556 & 0.611 \\
Residual sum of squares & 0.114 & 0.144 & 0.075 \\
\hline
\end{tabular}

\section{Maturing growth models}

OLS model

Maturing growth (M3) was negatively related to sockeye salmon abundance (SSAM3), and positively related to the 1976 to 1977 regime shift and M3 at lag yr 1, but not related to body size at the start of the marine growing season (L2) or M3 at lag yr 1 and 2 (Table 3 ) (SSR $=0.0869)$. The model explained $61 \%$ of the variation in M3.

\section{MARS model}

Maturing growth (M3) was associated with sockeye salmon abundance (SSAM3) and M3 at lag yr 1 and 2, but not with the 1976 to 1977 warm regime or size at the start of the marine growing season (L2) (Table 4). In the MARS model the residual sum of squares fell to 0.075 from 0.087 of the OLS model explaining $61 \%$ of the variation in M3 (Tables 4 \& 5). More importantly, the insignificant variable $M 3\{2\}$ in the OLS model became significant ( $t=3.57$ ) when it became part of an interaction with M3\{1\}. From the mid-1950s to the mid1980s, M3 increased $(t=6.16)$ when M3 at lag yr 1 was higher than average and increasing (Fig. 7a). As found 

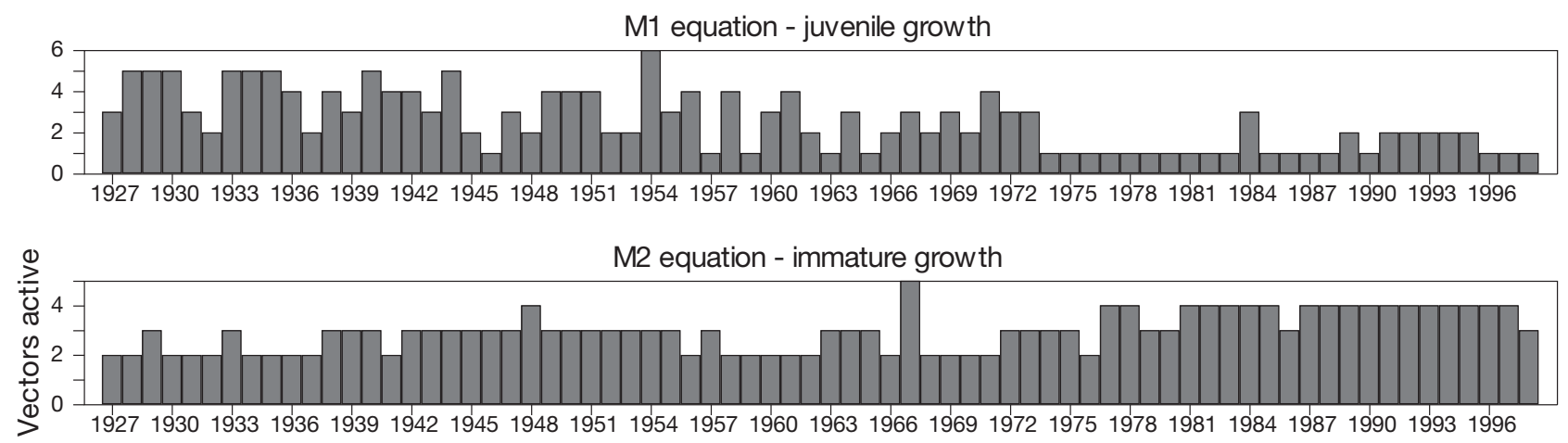

M3 equation - maturing growth

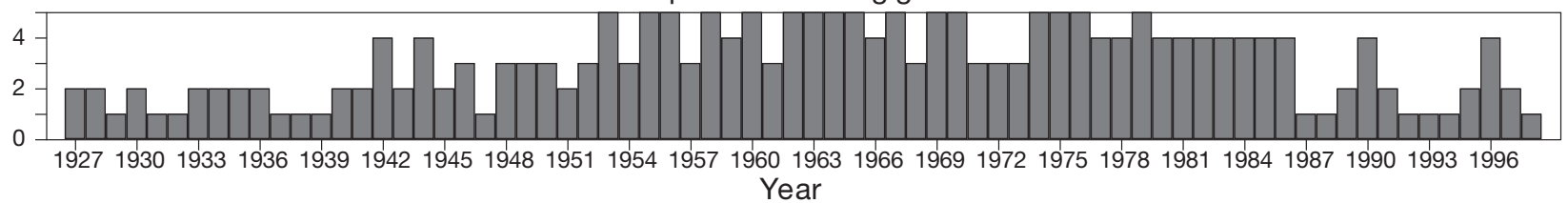

Fig. 4. Oncorhynchus nerka. Numbers of active vectors estimated with MARS for the juvenile (M1), immature (M2), and maturing (M3) growth models by year, as detailed in Figs. 5 to 7

$-0.932 \times \max (1.078-\mathrm{M} 1\{2\}, 0.0)$

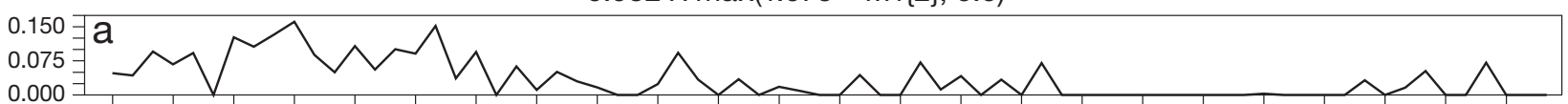

192719301933193619391942194519481951195419571960196319661969197219751978198119841987199019931996
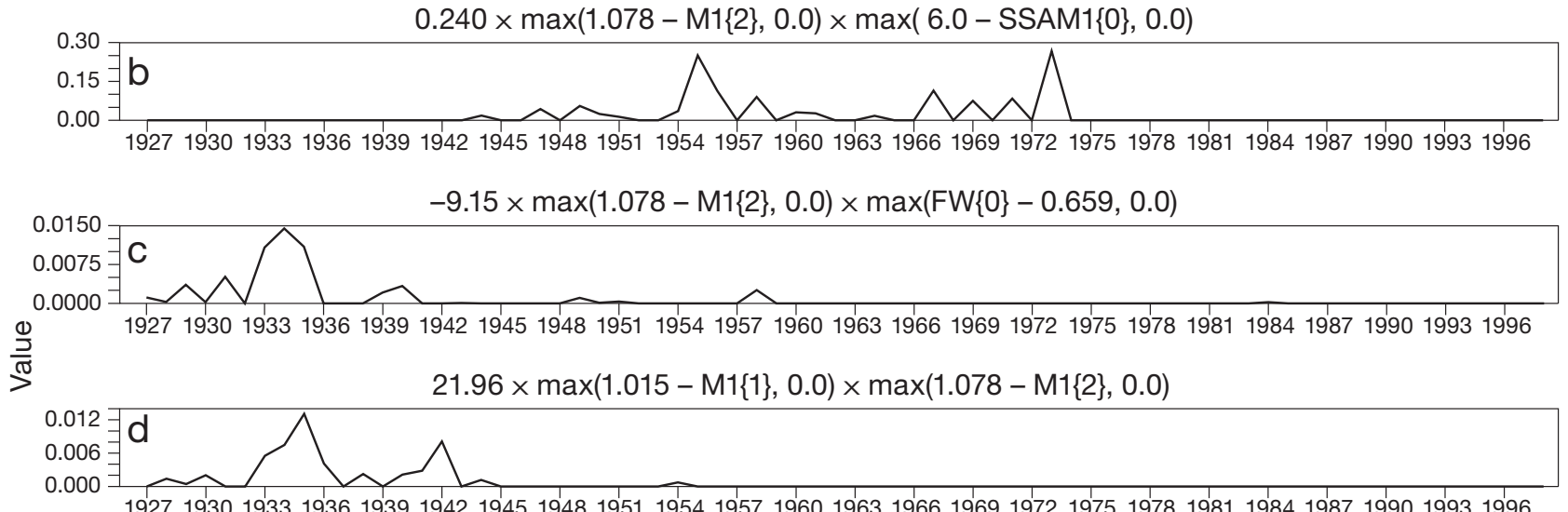

$-1.72 \times \max (1.015-\mathrm{M} 1\{1\}, 0.0)$

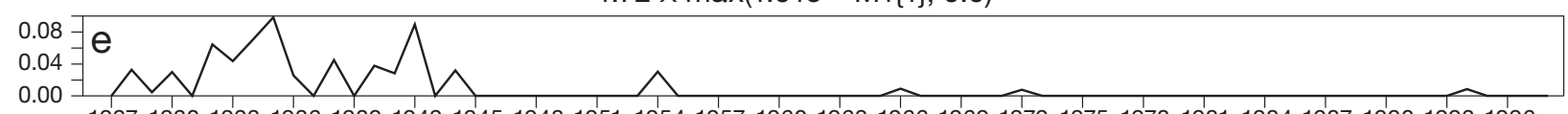

192719301933193619391942194519481951195419571960196319661969197219751978198119841987199019931996

$-1.23 \times \max (.621-\mathrm{FW}\{0\}, 0.0) \times \max (4.9-\mathrm{SSAM} 1\{0\}, 0.0)$

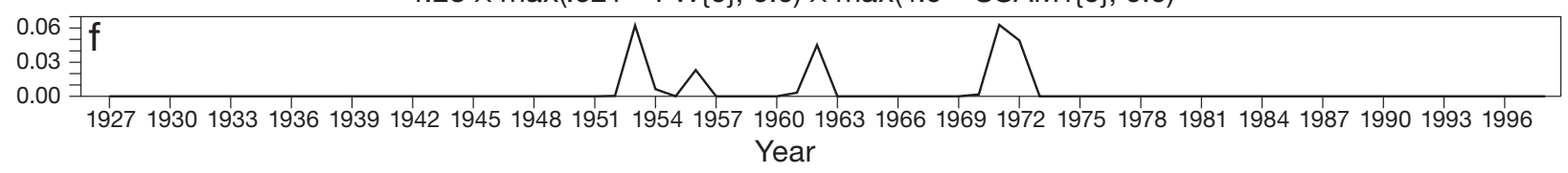

Fig. 5. Oncorhynchus nerka. Juvenile growth (M1) model showing the timing of the effects of the significant vectors, see results in Table 4. The magnitude of the effect on scale growth can be calculated as the coefficient multiplied by the value on the $y$-axis. Numbers in the titles for each graph are rounded values taken from the models reported in Table 4 


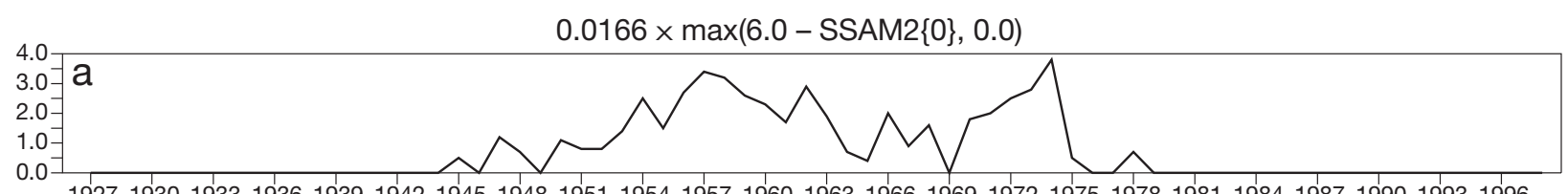

192719301933193619391942194519481951195419571960196319661969197219751978198119841987199019931996

$0.04354 \times \max (\mathrm{SHIFT}\{0\}-0.0,0.0)$
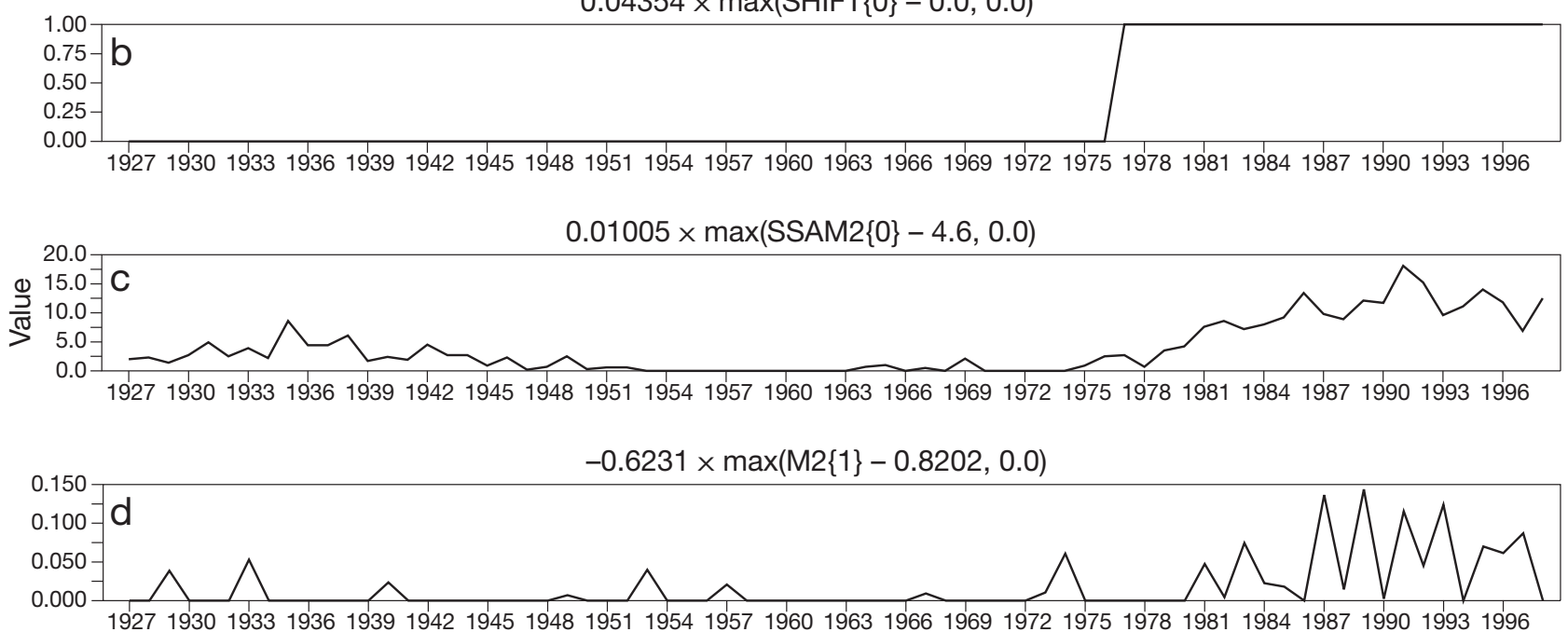

$-7.571 \times \max (0.820-\mathrm{M} 2\{1\}, 0.0) \times \max (1.663-\mathrm{L} 1\{0\}, 0.0)$

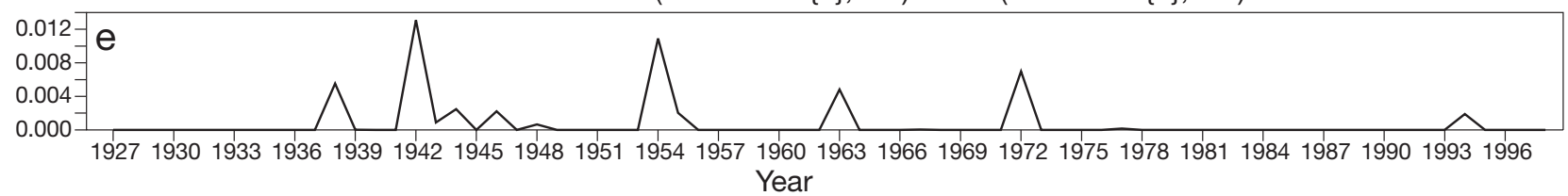

Fig. 6. Oncorhynchus nerka. Immature growth (M2) model showing the timing of the effects of the significant vectors; see results in Table 4. The magnitude of the effect on scale growth can be calculated as the coefficient multiplied by the value on the $y$-axis. Numbers in the titles for each graph are rounded values taken from the models reported in Table 4

with $\mathrm{M} 2$, in $35 \mathrm{yr}$, primarily during the cool regime, M3 increased $(t=4.40)$ when SSAM3 decreased below 6.8 million (Fig. 7b). M3 was significantly reduced ( $t=$ -4.50) when M3 at lag yr 1 and 2 were increasing in 16 yr between 1964 and 1985, especially in 1963, 1964 or 1963-64, 1970, 1975, and 1985 (Fig. 7c). For a similar period as that in the previous interaction term, there was a less significant increase in M3 $(t=4.17)$ (Fig. 7d). In 13 yr (1944, in even-numbered years from 1950 to 1962 , and in 1969, 1974, 1980, 1990, and 1996), M3 was reduced $(t=-4.10)$ when M3 at lag yr 1 was high and decreasing below 0.366 and M3 at lag 2 was increasing above 0.327 (Fig. 7e). Finally, a lesser increase $(t=3.57)$ in $\mathrm{M} 3$, during years similar to those in the previous model period, occurred when the M3 at lag yr 1 was increasing from low to high growth and decreasing from high to low for M3 at lag yr 2 (Fig. 7f). Replacing YEAR for SHIFT resulted in no significant change in the M3 versus SSAM3 relationship over time, but did result in a positive shift in M3 in 1974.

\section{Overall MARS results}

In the overall MARS models, sockeye salmon marine growth was negatively related to salmon abundance at lower abundances associated with the cool regime (Figs. 8 to 10). Juvenile growth (M1) decreased from high to low growth as juvenile sockeye salmon abundance (SSAM1) increased from 0 to 4.9 million (Fig. 8). M1 was further reduced as smolt size decreased below average and as SSAM1 decreased from 4.9 million to 0 fish (Fig. 8). Immature growth (M2) decreased as immature sockeye salmon abundance (SSAM2) increased from 0 to 6.0 million, whereas, when M2 of the previous cohort was high, there was a decrease in the magnitude of the reduction in M2 in relation to SSAM2 (Fig. 9). M2 increased as SSAM2 increased from 6.0 million to 22 million associated with warm regimes. Maturing growth (M3) decreased from high to average growth as maturing sockeye salmon abundance (SSAM3) increased from 0 to 6.8 million fish, and M3 


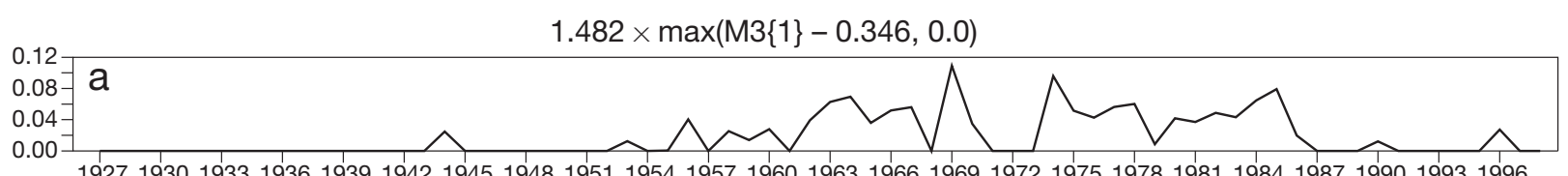

192719301933193619391942194519481951195419571960196319661969197219751978198119841987199019931996

$0.0135 \times \max (6.8-\operatorname{SSAM} 3\{0\}, 0.0)$

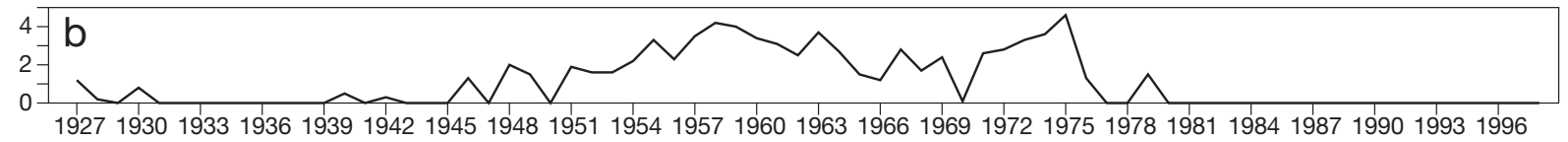

$-64.54 \times \max (\mathrm{M} 3\{1\}-0.346,0.0) \times \max (\mathrm{M} 3\{2\}-0.3819,0.0)$

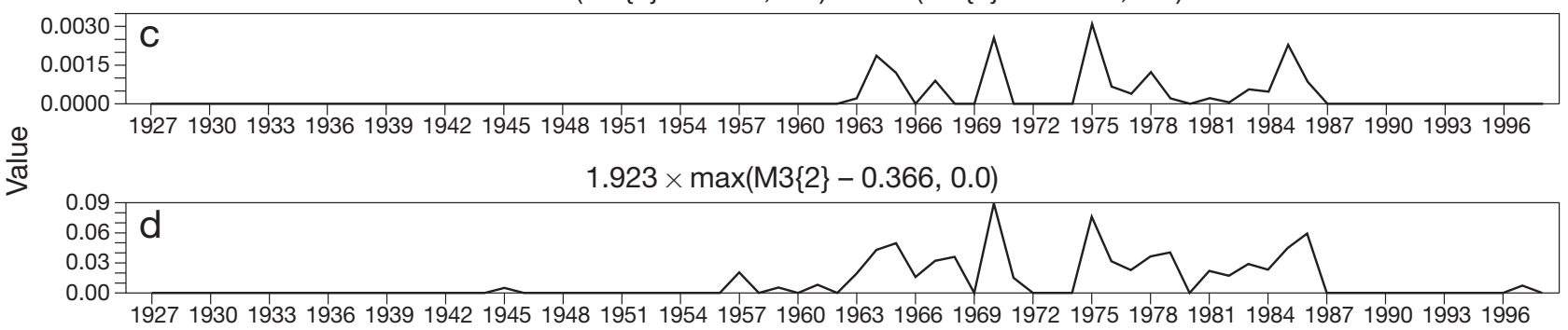

$-58.77 \times \max (\mathrm{M} 3\{1\}-0.327,0.0) \times \max (0.366-\mathrm{M} 3\{2\}, 0.0)$

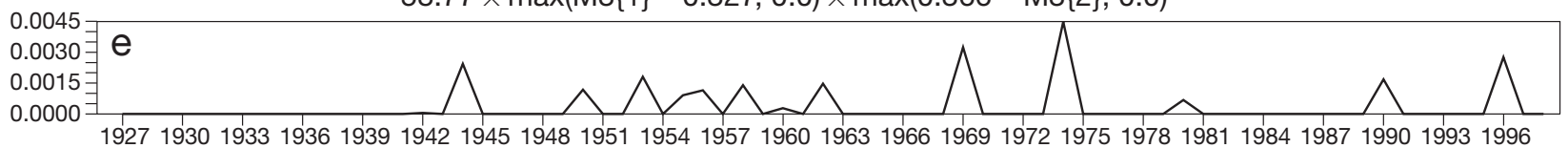

$29.82 \times \max (\mathrm{M} 3\{1\}-0.295,0.0) \times \max (0.366-\mathrm{M} 3\{2\}, 0.0)$

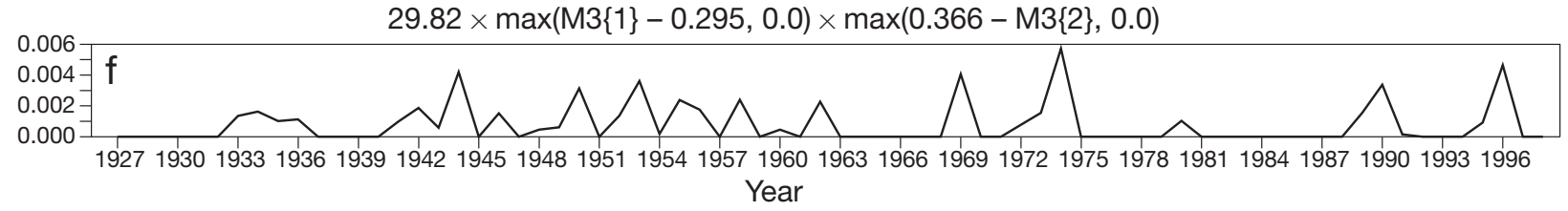

Fig. 7. Oncorhynchus nerka. Maturing growth (M3) model showing the timing of the effects of the significant vectors, see results in Table 4. The magnitude of the effect on scale growth can be calculated as the coefficient multiplied by the value on the $y$-axis. Numbers in the titles for each graph are rounded values taken from the models reported in Table 4

remained constant at higher abundances associated with cool regimes (Fig. 10). Both M3 at lag yr 1 and 2 had positive effects on M3 when $>0.35 \mathrm{~mm}$, while M3 lag 2 had a negative effect on M3 when $<0.35 \mathrm{~mm}$.

\section{DISCUSSION}

Density-dependent growth of ocean-dwelling salmon has been documented in correlation analyses of growth and abundance from the 1950s to the 2000s (Helle et al. 2007, Mathisen et al. 2007). In the present study, we examined the relationship between growth and abundance of Alaska sockeye salmon Oncorhynchus nerka from the mid-1920s to the late 1990s to deduce how density-dependent growth varied with climate regimes, population abundance, and body size. The MARS analysis allowed us to examine both the magnitude and dynamics of the growth and abundance relationship over time without having to impose the linearity assumptions implicit in the OLS method of analysis. Our primary findings were that intra-specific density-dependent growth of Karluk sockeye salmon occurred in all marine life stages, during the cool regime, at lower abundance levels, and at smaller sizes at the start of the juvenile stage.

Our results are based on the assumption that harvest is a reasonable proxy for abundances of salmon in the ocean over time, and that sockeye abundance fluctuates with climate (Finney et al. 2000). However, Alaska salmon catch has changed with management and gear (Colt 1999) that may affect our results. In 1924, the United States Congress established the White Act that required a $50 \%$ escapement goal for salmon in Alaska. During World War II (1938 to 1945), harvest of Alaska sockeye salmon varied by $20 \%$ around 7.9 million. In the central North Pacific Ocean, immature and maturing sockeye salmon were not likely intercepted by the drift-net fishing fleets from Japan that ended in 1992 (Pella et al. 1993). The effi- 


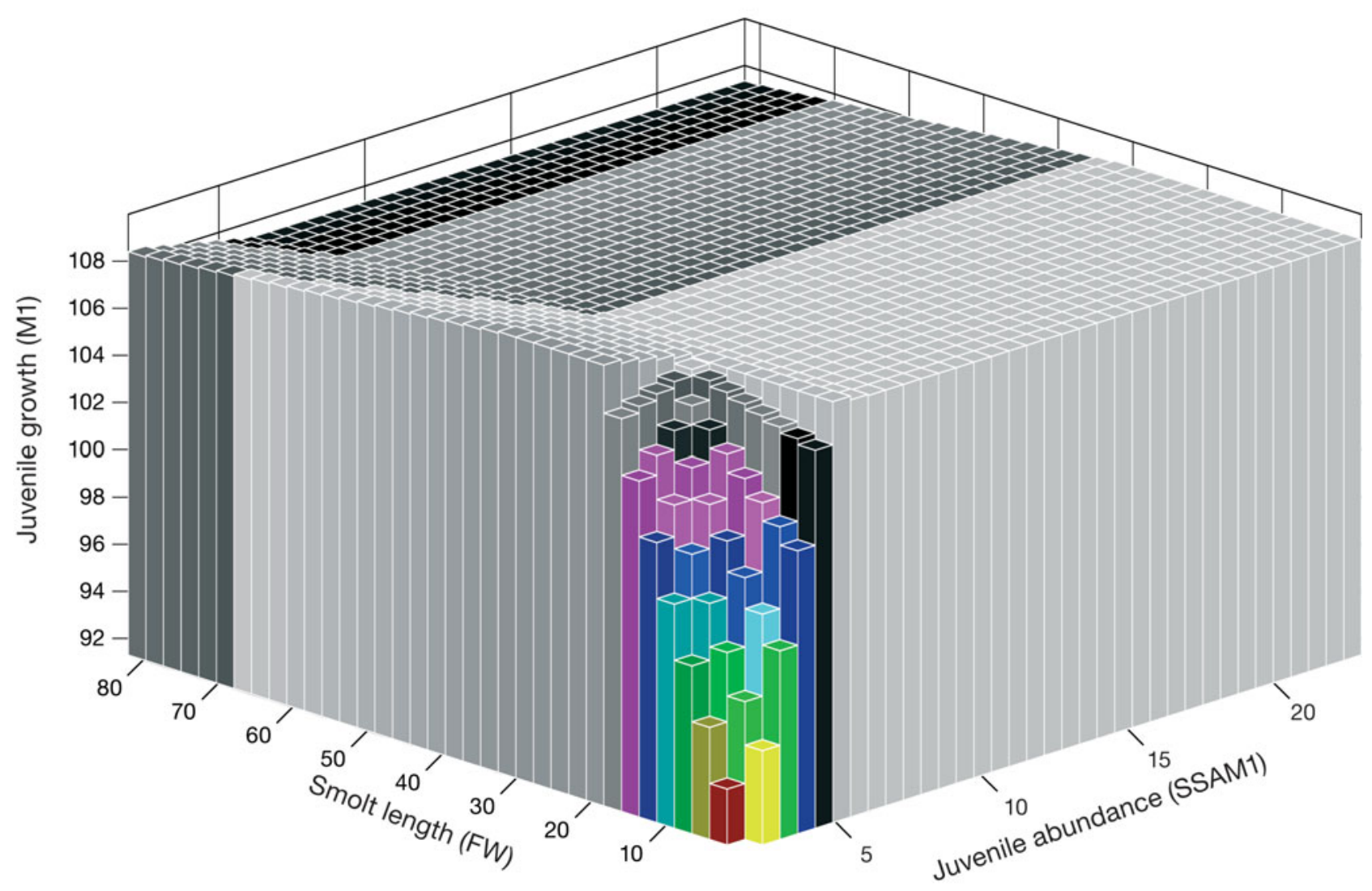

Fig. 8. Oncorhynchus nerka. Juvenile growth (M1) of age 2.2 sockeye salmon that returned to Karluk Lake, Alaska, in relation to the index of abundance for juvenile sockeye salmon from south central and southeast Alaska (SSAM1) and smolt size (FW). Models are in Table 4. Colors signify height of surface as indicated by z-axis

ciency (fish/gear) of purse seine and gillnets fished from a vessel, and large traps at mouths of bays and along shore was high from 1925 to 1950 and low from 1950 to 1970 and supports harvest as a proxy for abundance as indicated from catch rate (Colt 1999). With Alaska statehood in 1959, the ban on traps resulted in a 35\% increase in catch from 1961 to 1965 in comparison to years from 1955 to 1959. The increase in catch may have led to an under estimate of density-dependence during the cool regime. From the mid-1970s to the mid-1990s, increases in sockeye harvest in Alaska corresponded with a state mandate that limited the number of tradable entry permits in 1972, the construction of spawning channels for pink and sockeye in Canada, and warming of coastal waters that favored survival of Alaska salmon. A linear and positive relationship between the annual harvest rate (catch per boat/hour) of sockeye salmon and the total annual harvest of sockeye in Cook Inlet near Kodiak Island from 1979 to 1988 (Mundy et al. 1993) support using harvest as a proxy for abundance. In the 1990s, farmed salmon increased in market appeal to Japan and Canada and this change could have reduced catch of wild salmon and underestimated densitydependence during the 1977 to 1998 warm regime.

\section{Life-history stage and density dependence}

All marine life stages of Karluk sockeye salmon experienced density-dependent growth as inferred from inverse relationships between marine growth and sockeye salmon abundance. The magnitude of the density dependence increased with life stage. As sockeye salmon abundance increased from 2 to 6 million, the scale growth was reduced by $1 \%$ in the juvenile, 5 to $7 \%$ in the immature, and $20 \%$ in the maturing stage (Figs. 8 to 10). Several factors may increase the detection of density dependence through the life cycle. First, measuring the past growth histories on the scales of surviving adults does not include the density dependence experienced by non-survivors. Alternatively, maturing sockeye migrate through multiple marine habitats en route from oceanic water to their natal stream and may experience a wider range of habitats, prey fields, and com- 

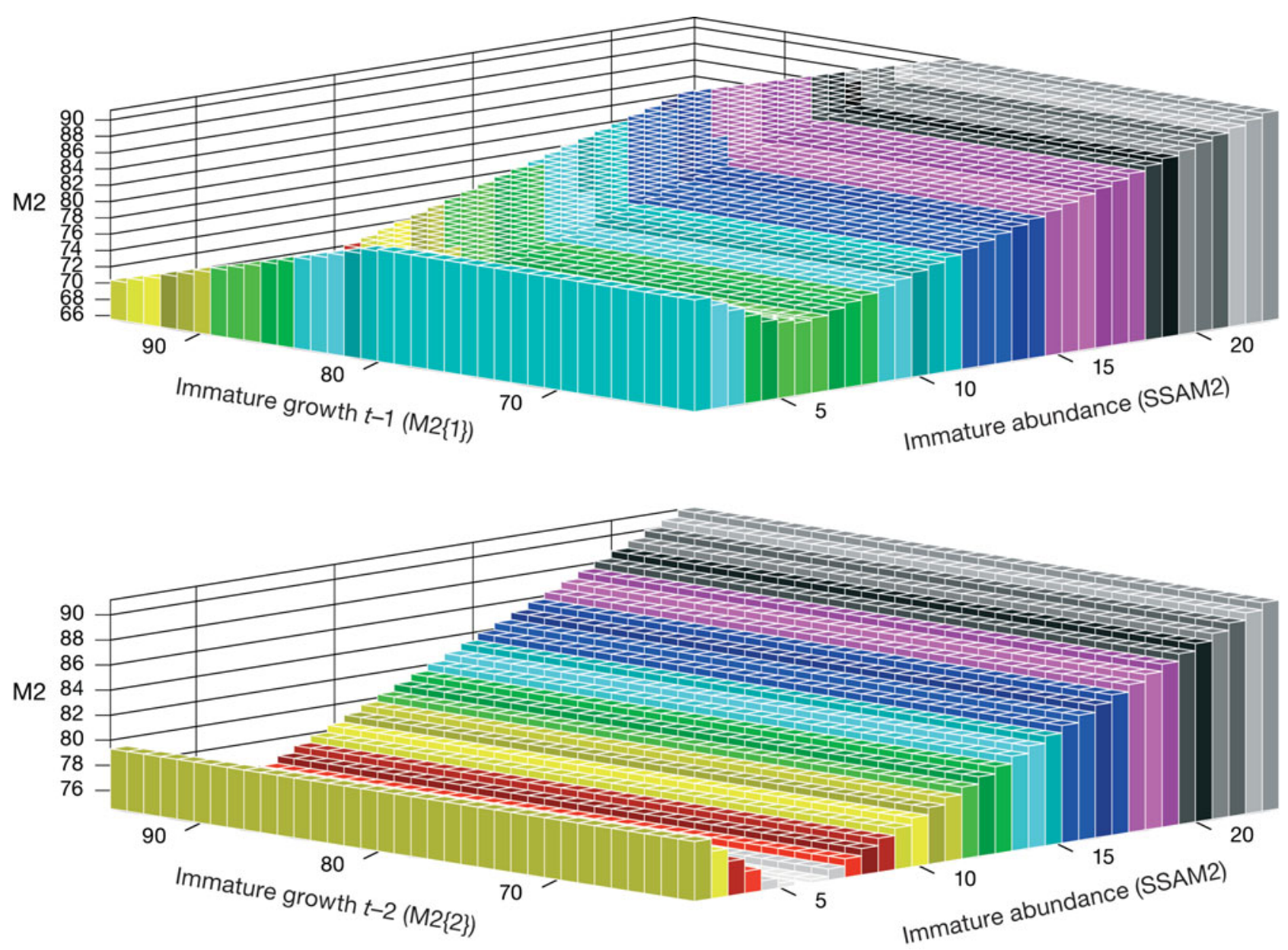

Fig. 9. Oncorhynchus nerka. Immature growth (M2) of age 2.2 sockeye salmon that returned to Karluk Lake, Alaska, in relation to the index of abundance for immature sockeye salmon from south central and southeast Alaska (SSAM2) and M2 of the 2 prior cohorts $(t-1, t-2)$. Models are in Table $4 . x$ - and $z$-axes are scaled by 100 . Colors: height of surface as indicated by $z$-axis

petitors than juveniles in continental shelf waters and immature sockeye in oceanic waters.

\section{Climate-oceanic regimes and density dependence}

The negative correlations between marine growth and salmon abundance during the cool regime in contrast to the positive correlation or lack of correlation between growth and abundance during the warm regimes suggests that density dependence was stronger during the cool regime than during the warm regimes. The warm regime climatic and oceanic conditions that favored the survival of Pacific salmon (Beamish \& Bouillon 1993) may have offset the densitydependent effects of higher sockeye salmon abundance. Alternatively, a $50 \%$ reduction in the abundance of piscivorous birds that fed on schooling fish in the Gulf of Alaska between 1972 and 1989 (Agler et al. 1999) led to an increase in forage fish abundances that provided competitors with alternatives to the preferred prey of sockeye. Cool regime conditions of low primary production (Venrick et al. 1987) could have reduced prey quality and quantity and increased competition for food among salmon. Additionally, if size-dependent mortality is severe during the cool, high-mortality regime, then a large number of larger and faster growing salmon, as indicated by the higher M1 and M3 scale growth in the cool regime, could have returned to the rivers (Farley et al. 2007). Results indicate that a scenario of higher abundances during a cool regime or excessively warm regime would result in a stronger density-dependent reduction in the marine growth of Alaska sockeye salmon.

\section{Salmon abundance and density dependence}

The negative growth and abundance correlations at a threshold of $<6.0$ million sockeye indicated that den- 

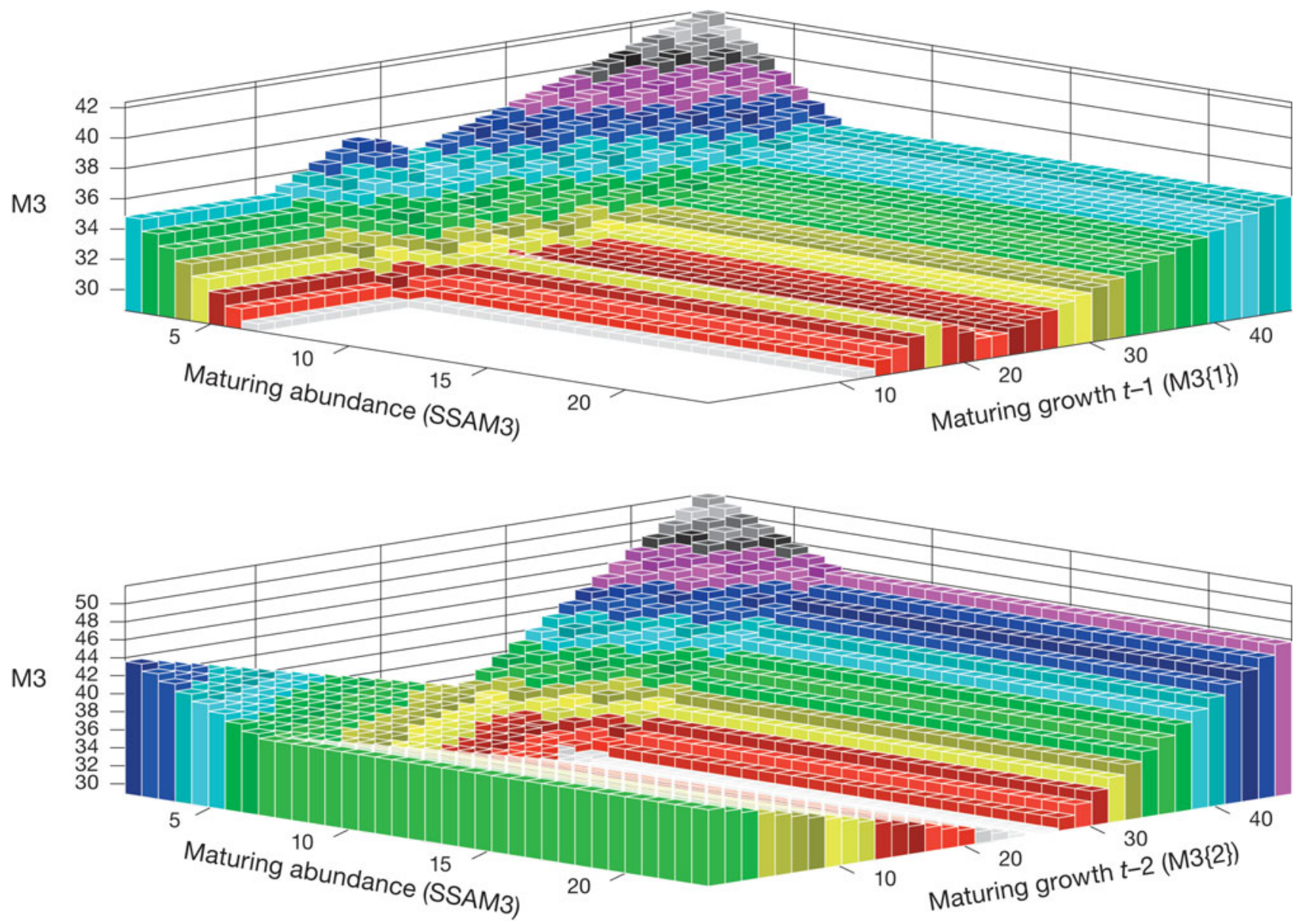

Fig. 10. Oncorhynchus nerka. Maturing growth (M3) of age 2.2 sockeye salmon that returned to Karluk Lake, Alaska, in relation to the index of abundance for maturing sockeye salmon from central and southeast Alaska (SSAM3) and M3 of the 2 prior cohorts $(t-1, t-2)$. Models are in Table 4. $x$ - and $z$-axes are scaled by 100. Colors: height of surface as indicated by $z$-axis

sity-dependent growth occurred at low population densities. Stream-dwelling salmonids often exhibit density-dependent growth at lower population densities (Jenkins et al. 1999). Competitors may deplete food resources by exploitative competition (Grant \& Imre 2005). Alternatively, the lack of observed densitydependence at higher abundance levels may be explained by interference competition, where a competitor blocks access to a food resource by increasing mortality or emigration and, in turn, reduces detection of density-dependent growth (Grant \& Kramer 1990).

\section{Body size and density dependence}

Smaller body size at the start of the juvenile growing season that interacted with the index of juvenile sockeye salmon abundance suggested that smaller size at the time of marine entry increases intra-specific competition among juvenile sockeye salmon. The reduc- tion in juvenile growth occurred when smolts were in the lower $25 \%$ size range and in years $(1953,1956$, 1962,1971 to 1972) of colder than average SST north of $20^{\circ} \mathrm{N}$ in the Pacific Ocean (Mantua et al. 1997). Following the cohort into an immature growing season showed that the smaller size and reduced juvenile growth transferred into reduced immature growth in 1954, 1963, and 1972 (Fig. 6e). Larger sockeye salmon may feed on higher quality and larger prey and thus gain a competitive advantage over smaller fish (Davis 2003).

\section{Alternate year patterns in growth}

The alternate year pattern of high and low growth suggests that growth is related to a process with a $2 \mathrm{yr}$ cycle. Possible explanations include interaction with a species with a 2 yr generation cycle such as pink salmon and or a physical oceanographic condition. For 
example, higher densities of the age 0.1 maturing pink salmon in odd-numbered years, in comparison to lower densities in even-numbered years, corresponded with slower growth rates of coho salmon in the western North Pacific Ocean, smaller body sizes of pink salmon in the central North Pacific Ocean, lower growth of Russian sockeye salmon, and reduced second- and third-year scale growth of adult sockeye that returned to Bristol Bay in western Alaska (Ogura et al. 1991, Walker 1998, Bugaev et al. 2001, Ruggerone et al. 2003).

The alternate year pattern of lower juvenile growth in the odd-numbered years 1929 to 1949,1967 to 1973 , and 1989, and 1995, and in the even-numbered years 1950 to 1964 and 1992 (Fig. 5a) corresponded with higher harvests of maturing pink salmon in the Kodiak management region near the Karluk River system in odd-numbered years from 1927 to the mid-1940s and in even-numbered years from 1954 to 1966. Although the diets of juvenile sockeye and pink salmon in coastal waters of the Gulf of Alaska overlapped from 25 to $79 \%$, the authors found no evidence of food limitations in 1996 (Auburn \& Ignell 2000). We hypothesize that sockeye salmon smolts out-migrating from the Karluk Lake into the Gulf of Alaska may compete for food with the maturing pink salmon returning to central Alaska rather than juvenile pink salmon. Maturing pink salmon feed on similar prey as do juvenile pink salmon, but consume larger sized prey, similar to juvenile sockeye (Auburn \& Ignell 2000, Davis 2003).

The lower immature growth in odd-numbered years than in even-numbered years from 1987 to 1997 (Fig. 6d) corresponded with higher densities of chum and pink salmon captured in gillnet surveys in the central Pacific Ocean in odd-numbered years from 1987 to 1997 (Azumaya \& Ishida 2000). At higher pink salmon abundances, immature chum salmon switched from eating higher quality crustacean and squid, preferred by sockeye and pink salmon, to eating lower quality gelatinous zooplankton in the North Pacific Ocean (Davis 2003). During odd-numbered years, immature and maturing sockeye salmon fed on $53 \%$ less of high-quality prey (euphausiids, copepods, squid, and fish) and $36 \%$ more of lower quality prey (pteropods and amphipods) in the central Bering Sea (Davis 2003).

Alternatively, a 2 yr cycle in the latitudinal position of the Sub-Arctic Current also corresponded with lower immature growth in odd-numbered years. In the 1994 to 1998 study, a more northern boundary was associated with cooler SSTs and larger salmon with higher quality diets of squid in 1996 and 1998, while a more southern boundary current was associated with warmer SSTs and smaller salmon with lower quality diets of zooplankton in 1997 (Aydin et al. 2000).

\section{CONCLUSIONS}

Although growth was measured on the scales of sockeye salmon that survived to maturity, densitydependent reductions in marine growth were detected in all marine life-history stages. The threshold analysis of the $74 \mathrm{yr}$ time series on growth and abundance indicates that the density-dependent growth of sockeye salmon varied with climate, population abundance, and body size. The finding that growth was negatively related to sockeye salmon abundance during the cool regime and lower abundance levels and positively related to sockeye salmon abundance at higher abundances during the warm regimes suggests that a shift to a cool regime or extremely warm regime at higher population levels may reduce the marine growth of salmon and increase competition for resources.

Acknowledgements. We thank Bill Lattyak from SCA for the SCA WorkBench software that provided an interface into the B34S Software used for MARS estimation (Stokes \& Lattyak 2006) and for his contributions to the initial model selection and interpretation. We also thank Dr. Peter Hagen, NOAA, for assisting with programming Optimate and setting up the digitizing system. Use of trade names does not imply endorsement by the National Marine Fisheries Service, NOAA.

\section{LITERATURE CITED}

Agler B, Kendall S, Irons D, Klosiewski S (1999) Declines in marine bird populations in Prince William Sound, Alaska coincident with a climate regime shift. Waterbirds 22: 98-103

Arnold E Jr (1951) An impression method for preparing fish scales for age and growth analysis. Prog Fish-Cult 13: $11-16$

Auburn M, Ignell S (2000) Food habits of juvenile salmon in the Gulf of Alaska July-August 1996. North Pac Anadromous Fish Comm Bull 2:89-98

Aydin K, Myers K, Walker R (2000) Variation in summer distribution of the prey of Pacific salmon Oncorhynchus spp. in the offshore Gulf of Alaska in relation to oceanographic conditions, 1994-98. North Pac Anadromous Fish Comm Bull 2:43-54

Azumaya T, Ishida Y (2000) Density interactions between pink salmon Oncorhynchus gorbuscha and chum salmon $O$. keta and their possible effects on distribution and growth in the North Pacific Ocean and Bering Sea. North Pac Anadromous Fish Comm Bull 2:165-174

Beamish R, Bouillon D (1993) Pacific salmon production trends in relation to climate. Can J Fish Aquat Sci 50: 1002-1016

Bigler B, Welch D, Helle J (1996) A review of size trends among North Pacific salmon Oncorhynchus spp. Can J Fish Aquat Sci 53:455-465

> Boylan P, Adams C (2006) The influence of broad scale climatic phenomena on long term trends in Atlantic salmon population size: an example from the River Foyle, Ireland. J Fish Biol 68:276-283

Brodeur R, Mills C, Overland J, Walters G, Schumacher J (1999) Evidence for a substantial increase in gelatinous zooplankton in the Bering Sea, with possible links to cli- 
mate change. Fish Oceanogr 8:296-306

Bugaev V, Welch D, Selifonov M, Grachev L, Eveson J (2001) Influence of the marine abundance of pink Oncorhynchus gorbuscha and sockeye salmon $O$. nerka on growth of Ozernaya River sockeye. Fish Oceanogr 10:26-32

Clutter R, Whitesel W (1956) Collection and interpretation of sockeye salmon scales. Int Pac Salmon Fish Comm Bull 9: $1-159$

Colt S (1999) Salmon fish traps in Alaska: an economic history perspective. ISER Working Paper 1999.1. Alaska Institute of Social and Economic Research Anchorage

Cushing DH (1971) The dependence of recruitment on parent stock in different groups of fishes. J Mar Sci 33:340-362

> Dahl K (1909) The assessment of age and growth in fish. Int Rev Gesamten Hydrogr Bull 2:758-769

Davis N (2003) Feeding ecology of Pacific salmon Oncorhynchus spp. in the central North Pacific Ocean and central Bering Sea, 1991-2000. PhD dissertation, Hokkaido University, Hakodate, Hokkaido

Doan T (2007a) Rats Version 7 reference manual. Estima, Evanston, IL

Doan T (2007b) Rats Version 7 user's guide. Estima, Evanston, IL

Eggers D, Irvine J, Fukuwaka M, Karpenko V (2003) Catch trends and status of North Pacific Salmon. North Pac Anadromous Fish Comm Doc 723:1-35

Farley E, Murphy J, Adkison M, Eisner L, Helle J, Moss J, Nielsen J (2007) Early marine growth in relation to marine-stage survival rates for Alaska sockeye salmon (Oncorhynchus nerka). Fish Bull 105:121-130

Finney B, Gregory-Eaves I, Sweetman J, Douglas M, Smol J (2000) Impacts of climate change and fishing on Pacific salmon abundance over the past 300 years. Science 290: 795-799

Friedland K, Hansen L, Dunkley D, MacLean J (2000) Linkage between ocean climate, post-smolt growth and survival of Atlantic salmon (Salmo salar L.) in the North Sea area. ICES J Mar Sci 57:419-429

Friedman J (1991) Multivariate adaptive regression splines. Ann Stat 19:1-50

- Fukuwaka M, Kaeriyama M (1997) Scale analyses to estimate somatic growth in sockeye salmon Oncorhynchus nerka. Can J Fish Aquat Sci 54:631-636

Fukuwaka M, Suzuki T (2000) Density-dependence of chum salmon in coastal waters of the Japan Sea. North Pac Anadromous Fish Com Bull 2:75-81

Grant J, Imre I (2005) Patterns of density-dependent growth in juvenile stream-dwelling salmonids. J Fish Biol 67: $100-110$

Grant J, Kramer D (1990) Territory sizes as a predictor of the upper limit to population density of juvenile salmonids in streams. Can J Fish Aquat Sci 47:1724-1737

Hare S, Mantua N (2000) Empirical evidence for North Pacific regime shifts in 1989. Prog Oceanogr 47:103-145

Hastie T, Tibshirani R (1986) Generalized additive models. Stat Sci 1:297-318

Hastie T, Tibshirani R (1990) Generalized additive models. Chapman \& Hall CRC, New York

Helle J, Hoffman M (1995) Size decline and older age at maturity of two chum salmon Oncorhynchus keta stocks in western North America, 1972-1992. In: Beamish J (ed) Climate change and northern fish populations. Can Spec Pub Fish Aquat Sci 121:245-260

Helle J, Martinson E, Eggers D, Gritsenko O (2007) Influence of salmon abundance and ocean conditions on body size of Pacific salmon. North Pac Anadromous Fish Comm Bull 4: 289-298
Ishida Y, Ito S, Kaeriyama M, McKinnell S, Nagasawa K (1993) Recent changes in age and size of chum salmon Oncorhynchus keta in the North Pacific Ocean and possible causes. Can J Fish Aquat Sci 50:290-295

Jenkins T, Diehl S, Kratz K, Cooper S (1999) Effects of population density on individual growth of brown trout in streams. Ecology 80:941-956

Kaeriyama M, Nakamura M, Edpalina R, Bower J, Yamaguchi H, Walker R, Myers K (2004) Change in feeding ecology and trophic dynamics of Pacific salmon Oncorhynchus spp. in the central Gulf of Alaska in relation to climate events. Fish Oceanogr 13:197-207

Kaeriyama M, Yatsu A, Noto M, Saitoh S (2007) Spatial and temporal changes in the growth patterns and survival of Hokkaido chum salmon populations in 1970-2001. North Pac Anadromous Fish Com 4:251-256

Koo T (1962) Age designation in salmon. In: Koo T (ed) Studies of Alaska salmon. University of Washington Publication Fish, NS Vol 1, University of Washington Press, Seattle, WA, p 37-48

Lees K, Pitois S, Scott C, Frid C, Mackinson S (2006) Characterizing regime shifts in the marine environment. Fish Fish $7: 104-127$

Lewis P, Stevens J (1991) Nonlinear modeling of time series using multivariate adaptive regression splines (MARS). J Am Stat Assoc 86:864-877

Manak D, Mysak L (1987) Climatic atlas of arctic sea ice extent and anomalies, 1953-84. Climate Research Group Report 87-8, Department of Meteorology, McGill University, Montreal, Quebec

Mantua N, Hare S (2002) The Pacific decadal oscillation. J Oceanogr 58:35-44

Mantua N, Hare S, Zhang Y, Wallace J, Francis R (1997) A Pacific interdecadal climate oscillation with impacts on salmon population. Bull Am Meteorol Soc 78:1069-1080

Martinson E, Masuda M, Helle J (2000) Back-calculated fish lengths, percentages of scale growth, and scale measurements for two scale measurement methods used in studies of salmon growth. North Pac Anadromous Fish Comm Bull 2:331-336

Mathisen O, Fair L, Beamish R, Bugaev V (2007) Densitydependent growth of sockeye salmon in the North Pacific Ocean. North Pac Anadromous Fish Comm Bull 4:299-310

Mueter F, Pyper B, Peterman R (2005) Relationships between coastal ocean conditions and survival rates of Northeast Pacific salmon at multiple lags. Trans Am Fish Soc 134: 105-119

Mundy P, English K, Gazey W, Tarbox K (1993) Evaluation of the harvest management strategies applied to sockeye salmon population of upper Cook Inlet, Alaska, using run reconstruction analysis. In: Proceedings of the international symposium on management strategies for exploited fish populations, AK-SG-93-02. Alaska Sea Grant College Program, Anchorage, AK

Myers K, Aydin K, Walker R, Fowler S, Dahlberg M (1996) Known ocean ranges of stocks of Pacific salmon and steelhead as shown by tagging experiments, 1956-1995. North Pac Anadromous Fish Comm Doc 192:1-229

Myers R, MacKenzie B, Bowen K, Barrowman N (2001) What is the carrying capacity for fish in the ocean? A metaanalysis of population dynamics of North Atlantic cod. Can J Fish Aquat Sci 58:1464-1476

Narver D (1968) Identification of adult sockeye salmon groups in the Chignik River system by lacustrine scale measurement, time of entry, and time and location of spawning. In: Burgner R (ed) Further studies of Alaska sockeye salmon. University of Washington Press, Seattle, WA, p 115-148 
Neave F (1949) Game fish populations of the Cowichan River. Bull Fish Res Board Can 84:1-32

Ogura M, Ishida Y, Ito S (1991) Growth variation of coho salmon Oncorhynchus kisutch in the western North Pacific. Bull Jpn Soc Sci Fish 57:1089-1093

Pella J, Rumbaugh R, Simon L, Dahlberg M, Pennoyer S, Rose M (1993) Incidental and illegal catches of salmonids in North Pacific driftnet fisheries. North Pac Anadromous Fish Comm Bull 53:325-358

Pitcher K (1990) Major decline in number of harbour seals, Phoca vitulina richardsi, on Tugidak Island, Gulf of Alaska. Mar Mamm Sci 6:121-134

Ricker W (1976) Review of the rate of growth and mortality of Pacific salmon in salt water and noncatch mortality caused by fishing. J Fish Res Board Can 33:1483-1524

Rogers D (1980) Density-dependent growth of Bristol Bay sockeye salmon. In: McNeil W, Himsworth D (eds) Salmonid ecosystems of the North Pacific. Oregon State University Press, Corvallis, OR, p 267-283

Royal L, Tully P (1961) Relationship of variable oceanographic factors to migration and survival of Fraser River salmon. Calif Coop Ocean Fish Invest Rep 8:65-68

Ruggerone G, Zimmerman M, Myers K, Nielsen J, Rogers D (2003) Competition between Asian pink salmon Oncorhynchus gorbuscha and Alaska sockeye salmon O. nerka in the North Pacific Ocean. Fish Oceanogr 12:209-219

Salo E (1988) Chum salmon as indicators of ocean carrying capacity. In: McNeil W (ed) Salmon production, management, and allocation. Oregon State University Press, Corvallis, OR, p 81-85

Scarnecchia D (1979) Variation of scale characteristics of coho salmon with sampling location on the body. Prog Fish-Cult 41:132-135

Editorial responsibility: Otto Kinne,

Oldendorf/Luhe, Germany
Scarnecchia DL (1981) Effects of streamflow and upwelling on yield of wild coho salmon (Oncorhynchus kisutch) in Oregon. Can J Fish Aquat Sci 38:471-475

Scarnecchia D (1984) Climatic and oceanic variations affecting yield of Icelandic stocks of Atlantic salmon (Salmo salar). Can J Fish Aquat Sci 41:917-935

Scarnecchia D, Isaksson A, White S (1989) Oceanic and riverine influences on variations in yield among Icelandic stocks of Atlantic salmon. Trans Am Fish Soc 118: 482-494

Shapovalov L, Taft A (1954) The life histories of the steelhead rainbow trout (Salmo gairdneri) and silver salmon (Oncorhynchus kisutch) with special reference to Waddell Creek, California, and recommendations regarding their management. Calif Dep Fish Game Fish Bull 98:1-375

Stokes H (1997) Specifying and diagnostically testing econometric models. Quorum Books, New York

Stokes H, Lattyak W (2006) Multivariate adaptive spline modeling using SCAB34S SPLINES and SCA Workbench. Scientific Computing Associates Corp, Villa Park, IL

Trenberth K, Hurrell J (1994) Decadal atmosphere-ocean variations in the Pacific. Clim Dyn 9:303-319

Trites A (1992) Northern fur seals: Why have we declined? Aquat Mamm 18:3-18

Trites A, Larkin P (1996) Changes in the abundance of Stellar sea lions (Eumetopias jubatus) in Alaska from 1956 to 1992: How many were there? Aquat Mamm 22:153-166

Venrick E, McGowan J, Cayam D, Mayward T (1987) Climate and chlorophyll $a$ : long term trends in the central North Pacific Ocean. Science 238:70-72

Walker R (1998) Growth studies from 1956-1995 collections of pink and chum scales in the central North Pacific Ocean. North Pac Anadromous Fish Comm Bull 1:54-65

Submitted: July 17, 2007; Accepted: July 24, 2008

Proofs received from author(s): October 8, 2008 